\title{
Welfare Reform in European Countries: A Microsimulation Analysis*
}

\author{
Herwig Immervoll, University of Cambridge, IZA and OECD \\ Henrik Jacobsen Kleven, University of Copenhagen, EPRU, and CEPR \\ Claus Thustrup Kreiner, University of Copenhagen, EPRU, and CESifo
}

Emmanuel Saez, UC Berkeley and NBER

Revised Version: June 2005

\footnotetext{
${ }^{*}$ We wish to thank Tony Atkinson, Marianne Bertrand, Jean-Philippe Cotis, Bertil Holmlund, Guy Laroque, David Dreyer Lassen, Peter Mueser, Thomas Piketty, Steve Pishke, Christian Schultz, two anonymous referees, and numerous seminar participants for helpful comments and discussions. We also thank Nicolaj Verdelin for outstanding computational assistance. Any remaining errors and views expressed in this paper are the authors' responsibility. In particular, the paper does not necessarily represent the views of the OECD, the governments of OECD member countries or the EUROMOD consortium. EUROMOD relies on micro-data from 11 different sources for fifteen countries. These are the European Community Household Panel (ECHP) made available by Eurostat; the Austrian version of the ECHP made available by the Interdisciplinary Centre for Comparative Research in the Social Sciences; the Living in Ireland Survey made available by the Economic and Social Research Institute; the Panel Survey on Belgian Households (PSBH) made available by the University of Liège and the University of Antwerp; the Income Distribution Survey made available by Statistics Finland; the Enquête sur les Budgets Familiaux (EBF) made available by INSEE; the public use version of the German Socio Economic Panel Study (GSOEP) made available by the German Institute for Economic Research (DIW), Berlin; the Survey of Household Income and Wealth (SHIW95) made available by the Bank of Italy; the Socio-Economic Panel for Luxembourg (PSELL-2) made available by CEPS/INSTEAD; the Socio-Economic Panel Survey (SEP) made available by Statistics Netherlands through the mediation of the Netherlands Organisation for Scientific Research - Scientific Statistical Agency; the Income Distribution Survey made available by Statistics Sweden; and the Family Expenditure Survey (FES), made available by the UK Office for National Statistics (ONS) through the Data Archive. Material from the FES is Crown Copyright and is used by permission. Neither the ONS nor the Data Archive bear any responsibility for the analysis or interpretation of the data reported here. An equivalent disclaimer applies for all other data sources and their respective providers cited in this acknowledgement. Financial support from European Commission grant SERD-2001-00099 (MICRESA project, Improving Human Potential programme), the Sloan Foundation and NSF Grant SES-0134946 is gratefully acknowledged. The activities of EPRU (Economic Policy Research Unit) are supported by a grant from The
} 


\begin{abstract}
This paper estimates the welfare and distributional impact of two types of welfare reform in the 15 (pre-enlargement) member countries of the European Union. The reforms are revenue neutral and financed by an overall and uniform increase in marginal tax rates on earnings. The first reform distributes the additional tax revenue uniformly to everybody (traditional welfare) while the second reform distributes tax proceeds uniformly to workers only (in-work benefit). We build a simple model of labor supply encompassing responses to taxes and transfers along both the intensive and extensive margin. We then use EUROMOD to describe current welfare and tax systems in European Union countries and use calibrated labor supply elasticities along the intensive and extensive margins to analyze the effects of the two welfare reforms. We quantify the equity-efficiency trade-off for a range of elasticity parameters. In most countries, because of large existing welfare programs with high phase-out rates, the uniform redistribution policy is undesirable unless the redistributive tastes of the government are extreme. The in-work benefit reform, on the other hand, is desirable in a very wide set of cases. We discuss the practical policy implications for European welfare policy.
\end{abstract}

Danish National Research Foundation. 


\section{Introduction}

Transfers to low-income individuals have grown significantly in Western Europe since World War II. Today, most European countries devote a sizeable amount of public spending to lowincome support through various programs such as unemployment insurance for those temporarily out of work, disability insurance for the disabled, housing and families subsidies for those with modest incomes or children, and various other income maintenance and welfare programs for those with no or very small incomes. Table 1 displays the fraction of government transfers in disposable incomes at each decile for 15 European countries for those aged 18 to 59. In all countries, such transfers represent a very large fraction of disposable income for the bottom deciles.

The proper amount of redistribution and the design of transfer programs is an important and controversial issue in the political sphere. As is well known among economists, redistribution gives rise to a trade-off between equity and efficiency. Redistribution from middle and high incomes to low incomes is desirable for equity reasons, because society puts a higher value on the marginal consumption of those with low incomes than on the marginal consumption of the well-off. However, redistributive programs tend to reduce incentives to work, thereby creating efficiency costs: to redistribute one additional Euro from high-income earners to lowincome earners, the government needs to impose a welfare cost larger than one Euro on those with high incomes. Smaller labor supply responses or greater social taste for redistribution imply that larger transfer programs and higher taxes are desirable.

Following the seminal contribution of Mirrlees (1971) on optimal income taxation, most studies on labor supply and redistribution issues have focused on the classic two-good static labor supply model where individuals supply labor such that their indifference curve between leisure and consumption is tangent to the budget constraint. Most studies on the welfare cost of taxation have adopted this labor supply model, e.g. Browning and Johnson (1984), Ballard (1988), and Dahlby (1998). Within this framework, optimal income tax theory shows that redistribution should take the form of a Negative Income Tax (NIT), where a lump-sum transfer given to everybody is quickly phased out as earnings increase. In this type of welfare program, transfers to those out of work are financed by positive tax burdens on middle- and high-income earners. There is a simple trade-off in the design of the program: the size of the 
transfer program and the level of taxes on middle and high incomes depends positively on the strength of redistributive tastes embodied in the social welfare function and negatively on the size of labor supply responses as reflected by the elasticity of labor supply with respect to the net-of-tax wage rate. In this context, the political debate on redistribution is a classical left-right debate, with the left arguing that redistribution is desirable and the right arguing that labor supply responses are large. We will refer to this debate as the old debate.

In the standard model, labor supply depends on the local slope of the budget constraint and responds only along the intensive margin: hours of work change a little bit when the marginal tax rate is changed a little bit. This stands in contrast to the political view blaming welfare programs for keeping individuals or families completely out of the labor force (e.g. Murray, 1984). Indeed, a central finding in the empirical labor market literature is that the extensive margin of labor supply (whether or not to work at all) is more important than the intensive margin (hours worked for those who are working). In particular, extensive labor supply responses tend to be strong at the bottom of the income distribution (Eissa and Liebman, 1996; Meyer and Rosenbaum, 2001). Joblessness has long been seen as an important issue in Europe, where many have blamed high unemployment rates on labor taxes and out-of-work transfers (e.g. Daveri and Tabellini, 2000). The discouraging effects of traditional welfare programs on participation have lead politicians to advocate programs that preserve work incentives. Such programs have been expanded on a large scale during the 1990s in the United States through the Earned Income Tax Credit (EITC) and in the United Kingdom through the Working Families Tax Credit (WFTC). These programs give no support for those with zero earnings, but provide earnings subsidies for workers with low earnings up to a maximum level above which the program is gradually phased out.

The recent theoretical analysis of Saez (2002) shows that the incorporation of extensive labor supply responses in the standard Mirrlees model changes the shape of the optimal tax schedule such that subsidizing the working poor (using negative marginal tax rates at the bottom) becomes desirable. Therefore, the new debate on welfare reform focuses to a smaller extent on the size of welfare programs and to a larger extent on the shape of the transfer programs and the incentives they create in the decision to enter or exit the labor force. The new debate asks if it is desirable to increase the incentives to work at the bottom by redistributing from the middle- and high-income earners to the working poor, rather than to non-workers as 
in the old debate.

This paper proposes to cast light on the welfare reform debates, both the old debate on traditional welfare programs and the new debate on redistribution towards the working poor. We construct a simple and fully explicit model of labor supply encompassing responses along both the intensive and extensive margins and we then apply the model to the analysis of welfare reform for 15 European Union countries using the EUROMOD micro-simulation model that has recently become available.

The EUROMOD micro-simulation model combines a tax and benefits calculator with detailed country-specific, but partly harmonised, micro data on income, earnings, labor force participation, as well as many demographic variables. For any set of household characteristics and country, EUROMOD is able to calculate the amount of benefits the household is entitled to and the taxes it should pay. EUROMOD has been constructed to incorporate all relevant tax and transfer programs in place in all countries that were members of the European Union prior to May 1, 2004. It is therefore a unique tool to obtain a complete picture of the incentives to work generated by those programs as well as the analysis of welfare reform. An introduction to EUROMOD and a descriptive analysis of taxes and transfers in the EU countries has been provided by Sutherland (2001), Immervoll (2004), and Immervoll and O'Donoghue (2003).

Using the EUROMOD model, we will first provide a description of the incentives to work generated by taxes and transfers along the extensive and intensive margins at each decile of the earnings distribution. Second and most important, we will evaluate the equity-efficiency tradeoff for two simple reforms corresponding to the old and new debates on welfare reform described above. We calibrate the elasticities of labor supply along the intensive and extensive margins using estimates from the empirical literature, and a careful sensitivity analysis will be provided. Like Browning and Johnson (1984) and others, we measure the equity-efficiency trade-off by the ratio of the "Euro value" of the welfare loss for those who lose from the reform to the "Euro value" of the welfare gain for those who gain. In other words, we calculate the number of units it would cost the rich to transfer an additional unit to the poor or the working poor.

The first reform we analyze corresponds to the old debate. This reform provides a uniform lump-sum grant to everybody financed by a uniform increase in the marginal tax rate on earnings for all groups in the population. This reform amounts to the standard NIT-type 
program: it provides more support for those with little or no earnings, but at the same time it weakens the incentives to supply labor along both the intensive and extensive margins. The second reform corresponds to the new debate. It consists in introducing an EITC-type program, where the net transfer to those out of work is kept unchanged. A uniform grant provided to all those who are working will be financed by a uniform increase in the marginal tax rate on earnings. This reform will induce some of those who are out of work to take a job (as the rewards for working increase at the bottom of the income distribution), but will reduce incentives to work along the intensive margin.

For most European countries, expanding the generosity of traditional welfare programs creates large efficiency costs: redistributing one additional Euro to low-income individuals by increasing welfare benefits typically requires a reduction in the welfare of high-income individuals by 2 to 4 Euros (depending on the particular country and the assumed labor supply elasticities). This is due to the fact that most European countries already impose quite large tax rates on the participation margin at the bottom of the earnings distribution. By contrast, expanding redistribution to the working poor is very cost effective as it will improve incentives to enter the labor market at the bottom of the distribution. As a result, the welfare cost of redistributing an additional Euro to the working poor might be very low (perhaps around 1 Euro, implying no additional deadweight burden).

Although many empirical studies on working poor policies allow for elasticities to differ at the extensive and intensive margins, most normative evaluations of potential tax and welfare reform consider behavioral responses only along the intensive margin. Our results stand in significant contrast to previous studies on tax and welfare reform in Europe (e.g. Bourguignon and Spadaro, 2002a,b) as well as in the United States (e.g. Triest, 1994; Browning, 1995), because we incorporate the extensive margin of labor supply response into the analysis. For example, the study by Browning (1995) finds that the large EITC program in the United States is an inefficient way to redistribute income in the standard labor supply model with only intensive margin responses. Interestingly, the recent study by Liebman (2002) incorporates fixed costs of work into the standard model (which amounts to introducing an extensive margin of labor supply response), and finds that the EITC is a quite efficient redistributive program in that context. Our results for Europe are consistent with Liebman's findings for the United States. In contrast to Liebman, we introduce directly and explicitly extensive elastici- 
ties, making our model more transparent and easier to calibrate from empirical labor supply studies. This paper should perhaps be considered a first step in the systematic analysis of tax and benefit reform within the European Union. We provide a framework which can easily be extended to consider more complex reform proposals and updated to incorporate future findings in empirical labor supply research.

The paper is organized as follows. Section 2 lays out the model of labor supply responses and the theoretical analysis of tax reforms. Section 3 describes the EUROMOD model, as well as the tax/transfer systems in the 15 European countries we analyze, and applies the theoretical framework to the practical analysis of welfare reform in each country. Finally, Section 4 offers some concluding comments, and discusses avenues for future research.

\section{Theoretical Analysis}

\subsection{Labor Supply Responses}

In this section, we propose a simple model to capture labor supply responses at both the intensive and the extensive margins. In order to capture extensive labor supply responses in a realistic way, it is necessary to introduce non-convexities in either the budget set or the preferences. In the standard convex model of individual behavior, marginal changes in prices and endowments give rise to marginal changes in behavior. However, empirical labor market studies have demonstrated that participation responses are poorly captured within such a framework (e.g., Blundell and MaCurdy, 1999). Indeed, the empirical evidence indicates that people choose either to stay out of the labor market or to work at least some minimum number of hours. Hence, we do not observe infinitesimal working hours for those who enter the labor market following a marginal increase in the net gain of work, but rather that they enter employment at, say, twenty or forty hours.

In a well-known paper, Cogan (1981) explained these discrete changes in labor supply behavior by the presence of fixed costs of working and showed empirically that such costs are important for the labor supply behavior of married women. In Cogan's analysis, the fixed costs of working may be monetary costs (say child care expenses), or they may take the form of a loss of time (e.g., commuting time). Below we adopt a simplified framework where these two types of fixed costs may be captured in a single parameter $q$. Within our framework, $q$ 
may also be interpreted as a distaste for participation/non-participation, or it may reflect the presence of stigma associated with being out of work. The size of $q$ will be allowed to vary across individuals.

In addition to heterogeneous fixed costs of working, the model also incorporates heterogeneity in abilities and preferences. In particular, we assume that the population may be divided into $J$ distinct groups with $N_{j}$ individuals in group $j$. Across groups, individuals differ with respect to productivity and preferences. Within each group, individuals are characterized by identical productivities and preferences, but they differ with respect to their fixed cost of working. By assuming a continuum of fixed costs, the model will generate a smooth participation response at the aggregate level of the group, such that we may capture the sensitivity of entry-exit behavior by setting elasticity parameters for each group.

An individual in group $j$ has an exogenous productivity $w_{j}$ and earns before-tax income $y_{j}=w_{j} l$ when supplying labor $l$. Assuming exogenous productivity is standard in tax models but is not an innocuous assumption. Indeed, one of the main motivations for in-work benefits is to encourage self-sufficiency and earnings progression. If individuals are rational about the positive human capital effects, then the theoretical analysis would not be fundamentally changed. However, if individuals are myopic, then encouraging work becomes even more desirable. We come back to this important point in the conclusion.

The individual faces a non-linear income tax schedule $T\left(y_{j}, z\right)$, where $z$ is an abstract shift parameter which will be used when analyzing tax reforms. The tax function constitutes a net payment to the public sector, embodying both taxes and transfers, and therefore $-T(0, z)$ defines the welfare benefit for those not working.

The assumption of identical within-group productivities and preferences implies that any individual who enters the labor market will do so at the same hours of work and earnings as all the other workers in his own group. While the participation decision is heterogeneous within the group (from heterogeneous fixed costs), the hours of work and income conditional on participation are not. Therefore without loss of generality, we may restrict ourselves to piece-wise linear tax schedules, letting each group face a given marginal tax rate and virtual income. Thus, we assume that any individual in group $j$ faces the marginal tax rate $\tau_{j}$ and has virtual income $I_{j}$. The same type of discrete formulation has been used by Dahlby (1998) to study the marginal cost of public funds in the standard convex labor supply model. Moreover, 
in the context of optimal tax analysis, Saez (2001) has shown that the optimal tax formulas depend essentially on average labor supply elasticities at each income level, implying that there is little loss in assuming a discrete set of ability groups, with uniform hours of work and earnings within each group.

In our static model, income net of taxes and transfers $y-T(y, z)$ is equal to consumption and is denoted by $c$. The utility function for an individual in group $j$ with fixed costs of working $q$, takes the following simple form:

$$
u_{j}(c, l, q)=c-v_{j}(l)-q \cdot 1(l>0)
$$

where $v_{j}($.$) is a convex and increasing function normalized so that v_{j}(0)=0$, and $1($.$) denotes$ the indicator function. In other words, the fixed cost of working $q$ is incurred whenever the individual decides to start working $(l>0)$. The above utility specification rules out income effects which simplifies considerably the theoretical analysis (Diamond, 1998, and Saez, 2001) and in particular welfare aggregation. ${ }^{1}$

Assuming no income effects on labor supply is broadly consistent with empirical studies on the labor supply of males (e.g., Pencavel, 1986). On the other hand, empirical studies suggest that there may be significant income effects for married women ${ }^{2}$ and single mothers (e.g., Blundell and MaCurdy, 1999). Our results should not be too sensitive to our assumption ruling out income effects for two reasons.

First, we are considering only balanced budget reforms and therefore income effects are quantitatively important for efficiency effects only insofar as they are large and substantially heterogeneous across different income groups. But the concern remains that married females and single females with kids tend to have lower earnings than prime-age males, so it might be the case that income effects will be more concentrated at the lower end of the income distribution.

Second, since both types of reform that we are going to analyze redistribute from highincome people to low-income people, the income effect would tend to decrease labor supply at the low end and increase labor supply at the high end in similar ways. Thus, to a first degree of approximation, the presence of income effects should not affect too much the comparison

\footnotetext{
${ }^{1}$ With income effects, there would no longer be a unique way to aggregate money metric utilities.

${ }^{2}$ Income effects for married women raises the complicated issue of spill-over effects from one spouse labor supply to the other, which is ruled out in our analysis with no income effects.
} 
between the two policies we are focusing on.

The individual chooses $l$ to maximize:

$$
u_{j}\left(w_{j} l-T\left(w_{j} l, z\right), l, q\right)=w_{j} l-T\left(w_{j} l, z\right)-v_{j}(l)-q \cdot 1(l>0) .
$$

In the case of participation, i.e. $l>0$, the optimum labor supply choice for an individual in group $j$ is characterized by

$$
W_{j}=\left(1-\tau_{j}\right) w_{j}=v_{j}^{\prime}\left(l_{j}\right),
$$

where $l_{j}$ denotes hours of work for a participating worker in group $j, \tau_{j}$ is the marginal tax rate for group $j$, and $W_{j}$ denotes the net-of-tax wage rate. The optimal hours of work depend only on the marginal net-of-tax wage rate $W_{j}$, not on virtual income. As discussed above, this implies that the intensive labor supply margin displays no income effects and therefore the compensated and uncompensated elasticities of labor supply are identical and fully characterize the intensive labor supply responses. Let us denote by $\varepsilon_{j}$ the intensive labor supply elasticity for an individual in group $j$. By definition, we have

$$
\varepsilon_{j}=\frac{W_{j}}{l_{j}} \frac{\partial l_{j}}{\partial W_{j}}
$$

For the individual to enter the labor market in the first place, the utility from participation must be greater than or equal to the utility from non-participation. This participation constraint gives rise to an upper-bound on the fixed cost of working, denoted by $q_{j}$ for individuals in group $j$. If we denote by $c_{j}=w_{j} l_{j}-T\left(w_{j} l_{j}, z\right)$ consumption when working and by $c_{0}=-T(0, z)$ consumption when not working, the upper-bound on the fixed cost may be written as

$$
q_{j}=c_{j}-c_{0}-v_{j}\left(l_{j}\right)
$$

Thus, individuals with a fixed cost below the threshold-value $q_{j}$ decide to work $l_{j}$ hours, while those with a fixed cost above the threshold $q_{j}$ choose to stay outside the labor force $(l=0)$.

Letting the fixed cost $q$ be distributed according to the distribution function $F_{j}(q)$ with density $f_{j}(q)$, the fraction of individuals in group $j$ who choose to participate in the labor market is given by $\int_{0}^{q_{j}} f_{j}(q) d q=F_{j}\left(q_{j}\right)$. At the aggregate level of group $j$, participation depends on $q_{j}$ which reflects the difference in utility between working (supplying $l_{j}$ hours) and not working (collecting benefits $c_{0}$ ) . Like the intensive margin, the extensive labor supply 
margin does not display income effects because increasing by the same amount taxes (or transfers) on those working and on those unemployed does not change the decision to start working.

Like Saez (2002), we define the extensive elasticity $\eta_{j}$ for group $j$ as the percentage change in the number of workers in group $j$ following a one-percent change in the difference in consumption between working and not working, $c_{j}-c_{0}$. Formally, we have

$$
\eta_{j}=\frac{c_{j}-c_{0}}{F_{j}} \frac{\partial F_{j}}{\partial\left(c_{j}-c_{0}\right)}=\frac{\left(c_{j}-c_{0}\right) f_{j}\left(q_{j}\right)}{F_{j}\left(q_{j}\right)} .
$$

We denote by $a_{j}=\left[T\left(w_{j} l_{j}\right)-T(0)\right] /\left(w_{j} l_{j}\right)$ the participation tax rate (as opposed to the marginal tax rate $\tau_{j}$ ).

The aggregate labor supply of group $j$ is thus equal to

$$
L_{j}=N_{j} F_{j}\left(q_{j}\right) l_{j}
$$

Hence, the total elasticity of labor supply with changes in the tax schedule can be decomposed into the intensive elasticity (affecting the amount of work $l_{j}$ for those working) and the extensive elasticity (affecting the number of individuals $F_{j}\left(q_{j}\right)$ who decide to work).

\subsection{The Equity-Efficiency Trade-Off}

The goal of this subsection is to study the effects of an arbitrary and small tax reform on utilities and tax revenue, and to derive a measure for the marginal trade-off between equity and efficiency. The effects will be expressed in terms of behavioral elasticities as well as various parameters of the current tax/transfer system. We then study two specific types of tax reform in more detail, namely a redistribution through an increase in the demogrant and a redistribution towards the working poor. Finally, we apply this theoretical analysis to 15 European countries using EUROMOD simulations in Section 3.

Redistributive policies providing income support for the poor or the working poor come at the cost of reduced incomes and welfare among high-income earners. In this paper, we will always consider welfare and tax reforms that are revenue neutral for the government budget. We will also consider infinitesimal reforms around the current tax and transfer system in order to keep the analysis as simple as possible. Let us consider a general small and revenue neutral tax reform $d z$. This reform creates losers and gainers. Given our utility specification with 
no income effects, the marginal utility of money is one for all individuals and welfare gains and losses can be simply aggregated across individuals. We denote by $d G \geq 0$ the aggregate welfare gains of those who gain from the reform and by $d L \leq 0$ the aggregate welfare change of those who loose from the reform. Note that in the case of a Pareto improving reform there are no losers and $d L=0 .^{3}$

Due to behavioral responses to taxes and transfers, the decline in welfare for the rich may potentially be much higher than the welfare gain for the poor (i.e., $d G+d L<0$ ), reflecting the distortionary effects of redistributive tax policy. A critical question then becomes how to evaluate the desirability of reforms involving such interpersonal utility trade-offs. The standard approach has been to specify a social welfare function involving certain welfare weights across individuals decreasing across the income distribution. Any given redistributive policy is then beneficial if it raises the value of the specified social welfare function. However, the interpersonal comparisons implied by the adopted welfare function are clearly subjective, and this limits the applicability of such an analysis as an input into the policy making process.

Following Browning and Johnson (1984), we divide the population into those who gain from the reform and those who lose from the reform. This partitioning of people will be endogenous both to the reform and to the behavioral responses created by the reform. This is an important point, which will be discussed later on when analyzing the distributional consequences of tax reforms. Within each of the two groups we assume a utilitarian welfare function. We then define the interpersonal utility trade-off $\Psi$ in the following way

$$
\Psi=-\frac{d L}{d G}
$$

If the reform constitutes an increase in redistribution, $\Psi$ gives the welfare cost to the rich from the transfer of one additional dollar of welfare to the poor (or the working poor). Conversely, if we are thinking about rolling back welfare programs, $\Psi$ is the cost to the poor per dollar transferred to the rich. This interpersonal trade-off may be interpreted as a critical value for the relative social welfare weight between the two groups, i.e., the relative weight on those who gain such that the reform breaks even in terms of social welfare. The trade-off measure used here was originally proposed by Browning and Johnson (1984), and subsequently used by Ballard (1988) and Triest (1994).

\footnotetext{
${ }^{3}$ In contrast, if the reform is Pareto worsening, there are no gainers and $d G=0$.
} 
The magnitude of $\Psi$ reflects the degree to which there exists a trade-off between equity and efficiency. In the case with no behavioral responses to taxes and transfers, redistributive taxation does not imply lower efficiency, and there is no change in aggregate utilitarian welfare from the reform. Thus, the welfare gain of those who gain (the denominator) exactly equals the welfare loss of those who lose (the numerator), implying that $\Psi$ is equal to one. Alternatively, a $\Psi$-value larger than one implies a trade-off between equity and efficiency (those who lose from the reform loose more than the gainers gain), whereas if $\Psi$ is less than one there is no conflict between the two and the reform actually increases efficiency.

To derive $\Psi$ for a general tax reform, we start by examining the impact on individual utilities from a marginal change in the reform parameter $z$. From eqs (2) and (3), we obtain

$$
\frac{d u_{j}(q)}{d z}=\left\{\begin{array}{ll}
-\partial T_{j} / \partial z & q \leq q_{j} \\
-\partial T_{0} / \partial z & q>q_{j}
\end{array},\right.
$$

where we have introduced $T_{j} \equiv T\left(w_{j} l_{j}, z\right)$ and $T_{0} \equiv T(0, z)$ to simplify notation. The effect on individual utility is given simply by the direct (mechanical) change in the tax liability since, by the envelope theorem, a marginal tax-induced change in hours of work or participation does not affect utility as labor supply is initially at its optimal level.

Since the reform experiments which we consider do not take money away from those who are unemployed, i.e. $\partial T_{0} / \partial z \leq 0$, we may include these individuals among the gainers in the denominator of the $\Psi$-measure. Moreover, by defining $G$ as the set of ability groups for which employed people gain from the reform, we may use eq. (9) to write $\Psi$ in the following way

$$
\Psi=-\frac{\sum_{j \notin G} \frac{\partial T_{j}}{\partial z} E_{j}}{\sum_{j \in G} \frac{\partial T_{j}}{\partial z} E_{j}+\frac{\partial T_{0}}{\partial z}(N-E)},
$$

where $E_{j} \equiv F_{j}\left(q_{j}\right) N_{j}$ denotes the number of employed people in group $j, E=\sum_{j} E_{j}$ is aggregate employment, and $N=\sum_{j} N_{j}$ is the total population.

Since we are considering redistributive policies, the tax reform is revenue neutral. It is central to note that this does not imply that the partial tax changes in the above expression sum to zero. Aggregating partial tax changes capture only the mechanical effect on government revenue, i.e., the effect in the absence of behavioral responses. Aggregate government revenue is given by

$$
R=\sum_{j=1}^{J}\left[T\left(w_{j} l_{j}, z\right) F_{j}\left(q_{j}\right) N_{j}+T(0, z)\left(1-F_{j}\left(q_{j}\right)\right) N_{j}\right]
$$


where the first component reflects tax revenue from employed people, while the second component is the (negative) revenue from those who are out of work. A small change in the reform parameter $z$ affects revenue in the following way

$$
\frac{d R}{d z}=\sum_{j=1}^{J}\left[\frac{\partial T_{j}}{\partial z} F_{j} N_{j}+\frac{\partial T_{0}}{\partial z}\left(1-F_{j}\right) N_{j}+\tau_{j} w_{j} \frac{d l_{j}}{d z} F_{j} N_{j}+\left(T_{j}-T_{0}\right) \frac{d F_{j}}{d z} N_{j}\right] .
$$

The revenue effect may be decomposed into mechanical changes (terms one and two) and behavioral changes along both margins of labor supply (terms three and four). Along the intensive margin, the reform induces employed people to adjust hours worked in response to a changed marginal net-of-tax wage $W_{j}$. At the same time, some individuals will be induced to enter or exit the labor market as the reform affects the net-of-tax income gain from entry $c_{j}-c_{0}$.

Using eqs (3)-(6), the above expression may be rewritten to

$$
\begin{aligned}
\frac{d R}{d z}= & \sum_{j=1}^{J}\left[\frac{\partial T_{j}}{\partial z} E_{j}+\frac{\partial T_{0}}{\partial z}\left(N_{j}-E_{j}\right)\right. \\
& \left.-\frac{\tau_{j}}{1-\tau_{j}} \frac{\partial \tau_{j}}{\partial z} \varepsilon_{j} w_{j} l_{j} E_{j}-\frac{a_{j}}{1-a_{j}} \frac{\partial\left(T_{j}-T_{0}\right)}{\partial z} \eta_{j} E_{j}\right] .
\end{aligned}
$$

For any given reform satisfying $d R / d z=0$, we may calculate the equity-efficiency tradeoff $\Psi$ from equation (10). The first two terms in equation (13) are the mechanical effect (which we denote by $d M$ ) of the tax reform. As we discussed above, because of the envelope theorem, the mechanical effects are exactly equal to minus the aggregate welfare effect $d W$ on the population. Let us denote by $d B$ the third and fourth terms in equation $(13) ; d B$ is the effect on tax revenue from the behavioral responses to the reform. Equation (13) and revenue neutrality then imply that $d W=d G+d L=d B$. Hence, the aggregate change in welfare (adding the gains of gainers and the losses of losers) following the reform is exactly equal to the behavioral effect on government revenue. Thus, $-d B$ can be seen as the extra deadweight burden generated by the reform. Our equity-efficiency measure $\Psi=-d L / d G$ is larger than one if and only if $d B<0$, i.e., the tax reform generates deadweight burden. For a given level of deadweight burden $-d B$, the larger the absolute value of gains and losses, the larger the amount of redistribution the reform achieves, and hence the smaller is $\Psi$.

In the following, we will concentrate on two simple tax reforms for which closed form expressions for $\Psi$ may be obtained. These two types of policies are chosen so as to illuminate 
some of the most important trade-offs which policy makers are facing in connection with welfare reform.

\subsection{Redistribution Through a Demogrant Policy}

In this section, we analyze a small welfare reform which redistributes income from high-wage earners in the labor market to individuals earning low wages and to those who are not employed. In particular, the reform under consideration takes the form of a demogrant policy which raises the tax rate on all units of labor income by $\tau$ and returns the collected revenue as a lump sum $T R$ to all individuals in the economy. This redistributive reform corresponds to an expansion of the traditional welfare programs financed by a general increase in tax rates.

The tax/transfer schedule is changed in the following manner:

$$
\frac{\partial \tau_{j}}{\partial z}=\tau, \quad \frac{\partial T_{j}}{\partial z}=\tau w_{j} l_{j}-T R, \quad \frac{\partial T_{0}}{\partial z}=-T R .
$$

Inserting these expressions in eq. (13) and setting $d R / d z$ equal to zero, we obtain

$$
T R \cdot N=\left[1-D_{d}\right] \cdot \tau \sum_{j=1}^{J} w_{j} l_{j} E_{j}, \quad D_{d} \equiv \sum_{j=1}^{J}\left(\frac{\tau_{j}}{1-\tau_{j}} \varepsilon_{j}+\frac{a_{j}}{1-a_{j}} \eta_{j}\right) s_{j} \geq 0
$$

where $s_{j} \equiv w_{j} l_{j} E_{j} /\left(\sum_{j=1}^{J} w_{j} l_{j} E_{j}\right)$ is group $j$ 's share of aggregate labor income. This expression shows that the aggregate lump sum transfer $T R \cdot N$ is equal to the direct increase in tax revenue from the imposition of $\tau$ multiplied by a factor $1-D_{d}$ reflecting the behavioral responses to the reform. Thus, a fraction $D_{d}$ of the mechanical tax revenue collections vanishes due to the behavioral responses to taxation, thereby reducing the amount of money which may be returned as a lump sum transfer. The fraction $D_{d}$ is an increasing function of the size of the labor supply responses measured by the elasticities $\varepsilon_{j}$ and $\eta_{j}$, and of the size of the tax rates of the current tax system measured by $\tau_{j}$ and $a_{j}$. Thus, in the special case of no labor supply responses along either the intensive or the extensive margins $\left(\varepsilon_{j}=\eta_{j}=0\right.$ for all $\left.j\right)$, there will be no behavioral revenue loss and therefore $D_{d}$ equals zero. Likewise, if the initial tax system is a non-distortionary lump sum tax $\left(\tau_{j}=a_{j}=0\right.$ for all $\left.j\right)$, we get $D_{d}=0$.

Finally, from eq. (15), we note that the revenue (and hence efficiency) effects created by the two margins of labor supply response are related to different tax wedges. While the intensive margin is related to the marginal tax rate $\tau_{j}$, the extensive margin is related to the tax rate on labor market entry $a_{j}$, which is an average tax rate including any transfers that 
are lost or reduced upon labor market entry. This difference between tax/transfer wedges will be important for the empirical application, a point emphasized by Kleven and Kreiner (2003) in the context of the marginal cost of public funds.

Now, using eqs (14) and (15), we may rewrite (10) as

$$
\Psi_{d}=1+\frac{D_{d}}{p_{g}\left(1-D_{d}\right)-s_{g}} \geq 1,
$$

where $p_{g} \equiv\left[\sum_{j \in G} E_{j}+(N-E)\right] / N$ denotes the population share for those who are gaining

from the reform, while $s_{g} \equiv \sum_{j \in G} s_{j}$ is the cumulative wage share for those who are gaining. ${ }^{4}$ If we are considering a tax reform creating no efficiency loss $\left(D_{d}=0\right)$, the interpersonal tradeoff is exactly one, i.e., an additional dollar transferred to the poor imposes a one-dollar cost on the rich. However, if the redistributive reform generates an efficiency loss $\left(D_{d}>0\right)$, and this is generally the case, it will cost more than one dollar of welfare for the rich to transfer one dollar to the poor.

\subsection{Redistribution to the Working Poor}

In this subsection, we compare the demogrant policy considered above with a reform which redistributes income to low-wage earners in the labor market, while keeping constant the income of those who are out of work. As before, the reform raises the tax rate on all units of labor income by $\tau$, but now the collected revenue is returned only to those who are working positive hours. Conditional on labor force participation, the transfer is lump sum. This type of reform may be interpreted as the introduction of an Earned Income Tax Credit (EITC) financed by higher taxes on high-wage earners.

The tax/transfer schedule is changed in the following manner:

$$
\frac{\partial \tau_{j}}{\partial z_{j}}=\tau, \quad \frac{\partial T_{j}}{\partial z}=\tau w_{j} l_{j}-T R, \quad \frac{\partial T_{0}}{\partial z}=0
$$

Inserting these expressions in eq. (13) and setting $d R / d z$ equal to zero, we obtain

$$
T R \cdot E=\left[1-D_{w}\right] \cdot \tau \sum_{j=1}^{J} w_{j} l_{j} E_{j}, \quad 1-D_{w} \equiv \frac{1-D_{d}}{1-\sum_{j=1}^{J} \frac{a_{j}}{1-a_{j}} \eta_{j} e_{j}} \lesseqgtr 1,
$$

where $e_{j} \equiv E_{j} / E$ is the employment share in group $j$. As with the analogous eq. (15) for the demogrant policy, the above expression shows that the aggregate lump sum transfer, now

\footnotetext{
${ }^{4}$ The denominator in eq. (16) captures the welfare gain of those who gain from the reform. Hence, the denominator is always positive.
} 
$T R \cdot E$, is given by the direct revenue increase multiplied by a parameter $1-D_{w}$ capturing behavioral responses to the reform. The essential difference to the previous equation lies in the denominator of the $(1-D)$-parameter, which reflects the positive participation response arising because the transfer is given only to employed people. Since this denominator is always less than one, the value of $D_{w}$ may be less than zero, implying that the behavioral feed-back effects on revenue may be positive on net. Consequently, a redistribution towards the working poor may increase overall efficiency.

Inserting eqs (17) and (18) into (10), we get

$$
\Psi_{w}=1+\frac{D_{w}}{e_{g}\left(1-D_{w}\right)-s_{g}},
$$

where $e_{g} \equiv \sum_{j \in G} e_{j}$ is the share of employed people gaining from the reform. ${ }^{5}$ In this expression, we have $\Psi_{w} \gtreqless 1$ iff $D_{w} \gtreqless 0$. It is now possible that the welfare cost to high-wage earners from the transfer of one dollar to low-wage earners is less than the dollar transferred. In this case there would be no conflict between equity and efficiency.

In the special case of no labor supply responses along the extensive margin $(\eta=0)$, the two types of tax reform which we have considered create identical behavioral responses (as the marginal tax rate is increased by $\tau$ in each case). It is illuminating to compare our efficiency and trade-off measures $D$ and $\Psi$ in this special case.

Eqs (15) and (18) show immediately that $D_{d}=D_{w}$, implying that the share of the projected mechanical increase in tax revenue which is lost through behavioral responses is the same for the two reforms. In other words, the additional deadweight burden, and hence the difference between gains $d G$ and losses $-d L$, is the same for the two reforms. While the difference between gains and losses is identical, the absolute magnitudes tend to be higher in the case of a demogrant policy. In the demogrant policy, the unemployed obtain transfers without paying any taxes, whereas in the working poor policy everybody getting transfers also pays taxes. For this reason, the aggregate gain of the gainers $d G$ and the aggregate loss of the losers $-d L$ will be higher for the demogrant policy. From the definition of the equity-efficiency trade-off in eq. (8), the larger magnitudes of both numerator and denominator (where the numerator is the larger number ) implies that $\Psi_{d}<\Psi_{w}$, i.e., the demogrant policy involves a more favorable trade-off than the in-work benefit reform. This result shows that, with no difference in the

\footnotetext{
${ }^{5}$ As with the demogrant policy, the denominator in eq. (19) is always positive, since it captures the welfare gain of those who gain from the reform.
} 
behavioral responses created by the reforms, the demogrant policy is "better" than the inwork benefits policy in the sense that it achieves more redistribution per dollar of deadweight burden. ${ }^{6}$

This difference in the trade-off for the two policies is part of a more general point. In general, the magnitude of $\Psi$ depends on the earnings distribution among the people affected by the reform. Consider the working poor policy, for example. Since tax payments depend on earnings, if the distribution of earnings is initially relatively equal (workers are almost identical), the net mechanical tax change (equal to the welfare effect) will necessarily be almost the same for each individual (i.e., gains and losses are close to zero). In other words, with an equal earnings distribution, we get little redistribution, and for a given efficiency loss $D$, the trade-off measure $\Psi$ becomes high. As the earnings distribution widens, gains and losses become bigger (more money is redistributed), and $\Psi$ becomes lower. This implies that, for given labor supply elasticities, in-work benefits will be more desirable in countries with large earnings disparities.

\section{Welfare Reform in Europe}

\subsection{Taxes and Transfers in European Countries}

\section{EUROMOD, Sample, and Tax Rate Definitions}

In the empirical part of this paper we make use of EUROMOD, an EU-wide micro-simulation model. The integrated nature of the model makes it a suitable tool for comparative policy analysis. EUROMOD is built around separate but partly harmonized household datasets describing the population of each country. Thanks to detailed algorithms representing existing tax and benefit legislation, the model is able to compute a range of tax and benefit amounts for each observation unit in a sample that is representative of the population as a whole. EUROMOD captures the full range of institutional features of tax and benefit systems. This includes detailed income definitions (such as taxable income or "means" relevant for computing income-tested benefits), precise definitions of family and assessment units (such as who counts as a "child" for the purpose of particular tax or benefit rules), thresholds, floors, ceilings and

\footnotetext{
${ }^{6}$ This is the main reason why papers analyzing models with only intensive labor supply responses such as Bourguignon and Spadaro (2000a,b) or Browning (1995) have found that traditional welfare is preferable to earned income tax credit schemes.
} 
relevant tax rates as well as specific eligibility rules, claw-back rates or income disregards used in computing benefit entitlements. The considerable level of detail makes it possible to derive a finely grained picture of tax burdens and benefit entitlements and how these vary with earnings and individual or family characteristics. Currently, the main policy instruments EUROMOD can simulate are income taxes, social security contributions (or payroll taxes) paid by employees, benefit recipients, and employers as well as universal and means-tested social benefits. Income components that are not simulated and are required as an input into the calculation of taxes and benefits (or the computation of total household incomes) are taken directly from the data. These include earnings, capital income and some insurance benefits which depend on long contribution histories not observed in the data. Further information on EUROMOD and the simulated tax-benefit instruments, including simulation details as well validation of model results against other sources, are provided by Sutherland (2001) as well as on the Internet at http://www.econ.cam.ac.uk/dae/mu/emod.htm.

An essential use of EUROMOD is the analysis of policy reforms and their effects on household income. However, the focus in the present paper is a different one. We need to compute net taxes, marginal effective tax rates as well as participation tax rates for existing policy configurations. We first compute employees' net taxes (income tax plus total social insurance contributions minus all social benefits) in the original situation and present them by gross earnings decile, gender and family type. In a second step, net taxes are recomputed after altering each employee's earnings to find marginal effective tax rates and participation tax rates (we come back to this below). Since EUROMOD takes into account interactions between different policy instruments (such as the taxation of benefits) and household members' incomes (e.g. in the case of benefits or taxes being a function of family rather than individual income) we are able to capture all relevant effects on total household income of an earnings change for a particular household member (see Immervoll, 2004 and Immervoll and O'Donoghue, 2003). The tax and benefit rules we consider are those that were in place in $1998 .^{7}$

In order to construct ten earnings decile groups, we define our sample as those aged 18 to 59 and who have been working full year and have positive annual earnings. We restrict the sample to full year workers because our model is static. In this context, we interpret part-year

\footnotetext{
${ }^{7}$ Since 1998, there have been a number of tax and transfer reforms in some of the countries we analyze.
} 
employees as being transiting between work and non-work at a point in time. ${ }^{8}$ We also exclude those who are currently receiving pension, early retirement, or disability benefits. Deciles are based on pre-tax earnings (including any social security contributions paid by employers). We estimate the number of non-working individuals by using Labour Force Survey employment participation rates.

The marginal tax rate is computed by increasing actual earnings $y_{j}$ of the individual by $3 \%$ and measuring the changes in all taxes and benefits, i.e., $\tau_{j}=\left[T\left(1.03 \cdot y_{j}\right)-T\left(y_{j}\right)\right] /(0.03$. $\left.y_{j}\right) .{ }^{9}$ In order to compute the participation tax rate, we first compute the difference between current household taxes and benefits and household taxes and benefits when the earnings of the individual are set to zero: $T\left(y_{j}\right)-T(0)$. We then divide this difference by earnings $y_{j}$ to obtain the participation tax rate $a_{j}=\left[T\left(y_{j}\right)-T(0)\right] / y_{j}$. Marginal tax rates and participation tax rates by decile for each country are displayed on Figures 1 and 2 respectively.

The theoretical analysis was based on a discrete formulation dividing the population into $J$ distinct subgroups. In the empirical application, we have to define these subgroups. Here it is important to choose a level of disaggregation which adequately captures the observed heterogeneity in the sample. Because tax rates, wage income and (potentially) labor supply elasticities are strongly heterogeneous and correlated across individuals, one could make substantial errors by aggregating too much. Our simulations will be based on a disaggregation into 10 earnings deciles where each decile is divided into 10 subgroups depending on gender and family type. ${ }^{10}$ We run simulations where elasticities are allowed to vary across deciles but are assumed constant across demographic groups within deciles, and we run simulations where elasticities are heterogeneous across both deciles and demographic groups. In the case of constant elasticities across demographic groups, we have compared our results from the disaggregated simulation runs (10 deciles $\times 10$ subgroups) to the results from simulation runs where demographic subgroups are aggregated. The results turn out to be virtually identical, which indicates that there is no reason to disaggregate further than we do because of heterogeneity

\footnotetext{
${ }^{8}$ In reality, regular part-year work such as seasonal work is also a possibility that we rule out in this analysis.

${ }^{9}$ Note that $+3 \%$ corresponds approximately to one additional hour of work for many full-time employees.

${ }^{10}$ Those ten groups are singles (no children), lone parents, married males (no children and working spouse), married males (no children and non-working spouse), married males (children and working spouse), married males (children and non- working spouse), married females (no children and working spouse), married females (no children and non-working spouse), married females (children and working spouse), married females (children and non-working spouse).
} 
in tax rates and wage income. ${ }^{11}$

\section{Typology of Taxes and Benefits}

Tables A1 and A2 summarize the main features of taxes and benefits (respectively) affecting the marginal and participation tax rates of workers in European countries.

All European countries impose three main types of taxes: income taxes, social security contributions (or payroll taxes), and consumption taxes. Income taxes are levied upon annual incomes (most of the time both employment and non-employment income with various deductions), in general with a progressive tax rate structure, and exemption levels. As a result, no income taxes are paid on very low incomes and marginal income tax rates for high income households can be substantial. ${ }^{12}$ Social security contributions (SSC) are levied on employment and sometimes benefit incomes and in general are designed to finance pensions, health, and unemployment benefits. They are often shared between employer and the employee and mostly have a simple flat rate structure with zero payments below a threshold and the contribution base capped above an upper limit. Frequently, thresholds give rise to discontinuities in the budget set since, once exceeded, the entire income is subject to contributions. Overall SSC rates can be substantial, especially in countries with large public pension and health insurance systems (and often exceed income tax rates). ${ }^{13}$ Finally, all European countries impose substantial consumption taxes in the form of Value Added Taxes (VAT) as well as excise taxes on specific goods (notably cars, gasoline, alcohol, and tobacco). Our tax computations incorporate both types of consumption taxes. The consumption tax rate is computed using data from OECD National Accounts and Revenue Statistics and are reported in Table A3, column (3). ${ }^{14}$ The rates center around 20 percent for most countries, while they are much higher in

\footnotetext{
${ }^{11}$ It should also be noted that we prefer to carry out simulations disaggregated to the level of decile $\times$ demographic group rather than completely disaggregated to the individual level due to outliers in the sample. Because of discontinuities in the budget sets created by some programs, marginal tax rates may be equal or larger than one for some individuals, in which case our formulas would be ill defined, and some ad-hoc truncation would be required.

${ }^{12}$ For example in France in 1998, only half of households are liable to the income tax and the top marginal income tax rate reaches $54 \%$.

${ }^{13}$ For example, for a worker with median earnings in Austria, Belgium, Greece and France combined employeeemployer SSC marginal tax rates sum to around $40 \%$.

${ }^{14}$ The calculation of consumption tax rates (CTR) is based on the methodology of Mendoza et al. (1994). See the notes to Table A3 for further details. To account for the effect of consumption taxes on the purchasing power of labor income, we use the tax rates in Table A3 to adjust the marginal tax rate $\left(\tau_{j}\right)$ and the participation tax rate $\left(a_{j}\right)$. The consumption-adjusted tax rates are given by the formula $(\mathrm{TR}+\mathrm{CTR}) /(1+\mathrm{CTR})$, where $\mathrm{TR}$ is the tax rate exclusive of consumption taxes.
} 
Finland and Denmark.

All European governments provide a number of benefits and transfers providing financial support to individuals and families with certain characteristics such as low income, unemployment, old-age or the presence of children. Benefits depending on income or employment status can have large effects on budget sets. Low-income groups often face very high marginal effective tax rates as a result of the tapering of means-tested benefits. We also see frequent discontinuities caused by work status conditions attached to out-of-work and in-work benefits or the non-gradual phase-out of benefit payments. ${ }^{15}$ We describe the main features of the relevant benefits in Table A2.

We can distinguish five main types of benefits. First, most countries operate social assistance benefits targeted towards those with no or very little income, and tapered away at high rates. For example, in France, the RMI (Revenu Minimum d'Insertion, or Minimum Income) provides about 400 Euros per month for a single person with no income and is phased out at a rate of $100 \%$. These minimum income benefits may be almost universal as long as the household meets income conditions (in France the only requirement is to be above 25), or can be targeted towards specific groups. Minimum income benefits are often more generous for certain groups such as single parent families, individuals with disabilities or older individuals (minimum pensions). Many European countries also provide housing benefits for families with low incomes.

Second, a number of benefits are conditional on certain characteristics and may not be targeted only to low incomes, although many of them are phased-out with earnings. For example family benefits are targeted to recent parents or to households with children more generally. In most cases, family benefits are not means-tested.

Third, a number of European countries provide in-work benefits targeted to those who are currently working or are moving into work. The first European countries to introduce in-work benefit programs were the United Kingdom (in 1988) and Ireland (in the early 1990s). In 1998, the year on which our study is based, the Family Credit in the UK provided a substantial benefit to all families with children if one parent works at least 16 hours a week and earnings are below

\footnotetext{
${ }^{15}$ For example, in Luxembourg and Belgium (in 1998) housing benefits for single parent families are not withdrawn smoothly but drop to zero at a specified income threshold.
} 
a given modest level. ${ }^{16}$ Since 1998, a number of other European countries have introduced in-work benefits. France introduced such a program as of 2001 ("Prime Pour l'Emploi" or premium for employment). The Netherlands introduced an Employment Tax Credit in 2001, while Belgium has been phasing-in an Earned Income Tax Credit program from 2002 to 2004. Germany introduced the so-called "Mainzer Modell" program in 2002 which, more recently, has been replaced by SSC reductions available to low-wage earners. Finland has recently introduced and then expanded an Earned Income Tax Allowance, and Denmark introduced a similar type of program on a small scale in 2004. Finally, while the Italian family benefit has not normally been considered an in-work benefit, it increases with the number of days worked. In all cases, the new in-work benefits programs in Europe are still small relative to the in-work benefit programs in the United Kingdom, Ireland, or the United States (see OECD, 2004). Except for those countries, our results can be interpreted as the welfare analysis of introducing modest in-work benefits programs in a situation where such programs did not yet exist.

Fourth, all countries operate unemployment insurance benefits which are generally temporary (they expire after some maximum duration) and/or conditional on participating in some type of active labor market program. By definition, unemployment insurance benefits are meant to replace lost earnings due to job loss. In our simulations, computing income measures with and without work requires a special treatment of unemployment benefits as their duration is limited and not all unemployed individuals are currently receiving them (but may instead receive lower social assistance or means-tested benefits where these are available). Furthermore, unemployment benefits are generally only available following the loss of a previous job. Attributing to each non-working person the full amount of unemployment benefits that would initially be available to an unemployed person would overstate the value of benefits when out of work. Unemployment benefits, by narrowing the difference in disposable income when working and when not working, increase substantially the participation tax rate but, except where they are affected by the spouse's earnings, generally have no effect on the marginal tax rate of those in work. As a result, in the presence of positive labor supply participation elasticities, unemployment benefits certainly contribute to making in-work benefits more de-

\footnotetext{
${ }^{16}$ The United States introduced the Earned Income Tax Credit (EITC) in the 1970s. While the program was initially very modest, a number of EITC expansions in the 1980s and especially in the 1990s turned it into the single largest cash transfer program for lower-income families at the federal level. The US experience has lead many other countries to adopt similar programs.
} 
sirable than the demogrant policy. We therefore adopt the following conservative approach in assigning unemployment benefits to out-of-work individuals. For each country as of 1998, we estimate the number of unemployed adults entitled to unemployment benefits by combining OECD Labour Force Survey statistics on the unemployed by duration of unemployment in conjunction with information on statutory duration limits on unemployment benefit receipt for each country. We then compute the ratio $\rho$ of those benefit recipients to the total number of non-working adults of working age in the economy (using again OECD labour force statistics). The resulting ratios are reported for each of the 15 countries in column (2) of Table A3 in Appendix.

We compute marginal and participation tax rates as the weighted average of the rates estimated including fully unemployment benefits (weight $\rho$ ) and excluding fully unemployment benefits (weight $1-\rho$ ). In principle, the ideal weight to use would be the fraction getting unemployment benefits when leaving employment because of the reform, and the fraction who were getting unemployment benefits among those starting employment because of the reform. Those propensities of getting/loosing unemployment benefits for the marginal worker/non worker are not observed in the data and we therefore rely on the propensity of getting benefits for the average person not working. Because those entitled to unemployment benefits are in principle looking for work, they are perhaps closer to employment than the average non-working person, suggesting that our measure of unemployment benefits is probably too conservative. $^{17}$

Fifth, all European countries provide public pension benefits. Those benefits are ignored in the present simulations because we focus on the population aged 18 to 59 , and we exclude from our sample all individuals currently receiving pension or disability benefits. Note that unemployed persons may have access to disability benefits which can be substantially higher than unemployment benefits. The main reason we rule out pensions and retirement/disability decisions from the analysis is because such decisions do not fit well in the static labor supply model we use and are best analyzed in a dynamic life cycle model. Such an analysis would also require retirement decisions elasticities rather than traditional static labor supply elasticities. ${ }^{18}$

\footnotetext{
${ }^{17}$ In order to assess the sensitivity of our results to the inclusion of unemployment benefits, we will also provide results in the case where we exclude completely unemployment benefits (this situation is most favorable to the demogrant policy relative to the in-work benefits policy and is obviously too conservative).

${ }^{18}$ Gruber and Wise (1999) examine a large number of OECD countries and show that the design of retirement benefits systems has a strong impact on the retirement decision.
} 
It should be emphasized however that retirement (or disability) decisions could be affected by taxes and other benefits. For example, an in-work benefit could induce some individuals to delay retirement or not to claim disability benefits. More generous traditional welfare might also induce some individuals to collect welfare rather than disability benefits. Such spill-over effects should be taken into account for a complete analysis but are ignored in the present study for sake of simplicity. ${ }^{19}$

Finally, we note that many countries provide benefits using indirect subsidies for some expenditures such as public housing, child care, or kindergarten. Such in-kind benefits which are not tied specifically to income are not currently incorporated in the EUROMOD model. We ignore such subsidies in the present study.

\section{Marginal Tax Rates and Participation Tax Rates in Europe}

Figures 1 and 2 report the marginal and participation tax rates respectively in the 15 European countries we study (Annex Tables A1 and A2 provide details on the institutional features giving rise to the observed rates). Countries are divided into three groups: (a) is Nordic countries (Denmark, Finland, Sweden), (b) Continental Europe (Austria, Belgium, France, Germany, Luxembourg, and the Netherlands), (c) Anglo-saxon and Southern European countries (Greece, Ireland, Italy, Portugal, Spain, and the United Kingdom). Broadly speaking, tax rates tend to be highest in Nordic countries, relatively high in continental Europe ${ }^{20}$ and lowest in Anglo-saxon and Southern European countries.

In a number of countries, the structure of tax rates across deciles is strikingly flat. For example, in the Netherlands the participation tax rate is between 57 and 62 percent in all deciles. Belgium, Finland, Italy, and Portugal also have relatively flat rate structures. This suggests that, to the extent that decile groups are homogeneous, the tax/transfer system of those countries is relatively close to a pure Negative Income Tax system combining a demogrant and a constant marginal tax rate on earnings.

Marginal rates do not always increase monotonously. There are several reasons for this. Joint tax systems as in France or Germany can result in very high marginal income tax

\footnotetext{
${ }^{19}$ We also exclude full time students from the analysis. Educational decisions are also best modelled in a life cycle set-up although they can interact with the tax and transfer system.

${ }^{20}$ Luxembourg is an exception. As other smaller and very wealthy European countries or principalities such as Liechtenstein or Switzerland, tax rates are significantly lower in Luxembourg than in other larger continental European countries.
} 
rates for low-wage spouses of high-income earners. In addition, the withdrawal of incomerelated benefits can increase marginal tax rates at the bottom. Also, SSC schedules are often characterized by discontinuities such as earnings thresholds which can give rise to very high marginal rates (as well as participation tax rates) for some low-wage earners. At the same time, caps on the contribution base can result in lower marginal SSC rates for the highest deciles. In France, earners of very low wages benefit from reduced employers' SSC which lowers marginal rates in decile 1 significantly. For higher earnings, however, these reductions are withdrawn adding to overall marginal rates and contributing to a marked increase between decile 1 and 2. Finally, indirect taxes also contribute to a flattening of the tax rate profiles.

In countries such as Denmark and Sweden, participation tax rates are largest at the bottom because the implicit tax on working created by generous earnings- and work-tested benefits weigh more heavily on low-income people. Moreover, unemployment insurance benefits can be subject to a floor so that replacement rates for low-wage earners can be very high in some cases. In contrast, countries such as Greece, Luxembourg, Spain, and the United Kingdom have relatively lower tax rates at the bottom because minimum income programs do not exist or are modest relative to in-work earnings, because tax burdens on employment incomes are small and/or because they operate in-work benefits which partly offset the loss of social assistance or unemployment benefits.

\section{Income Distribution}

Figure 3, Panel a and b display the P90/P10 and P80/P20 ratios (respectively) by countries for those with positive earnings. As is well known, Nordic countries have the lowest level of earnings inequality while Anglo-saxon countries have the highest. As we discussed above, larger earnings disparities will make our reforms, and especially the in-work benefit, more desirable as it spreads gains and losses more widely in the population.

\subsection{Empirical Literature and Calibration}

A central finding in the empirical labor market literature, recently surveyed by Blundell and MaCurdy (1999), is that labor supply tends to be quite unresponsive along the intensive margin. While it has long been recognized that the hours-of-work elasticity for prime-age males is close to zero, more recent research has demonstrated that this is also the case for 
females. The old findings of high elasticities for women (especially married women) were based on censored specifications including non-participating individuals, thereby including the extensive response in the estimated elasticity. Once labor supply is estimated conditional on labor force participation, it turns out that the female hours-of-work elasticity is close to that of males (Mroz, 1987; Triest, 1990).

Hence, a strong degree of labor supply responsiveness would have to come from the margin of entry and exit in the labor market. Indeed, there is an emerging consensus that extensive labor supply responses may be much stronger than intensive responses (e.g., Heckman, 1993). In particular, participation elasticities seem to be very high for certain subgroups of the population, typically people in the lower end of the earnings distribution. Let us briefly review some of the evidence, emphasizing studies based on tax policy experiments which are our concern here.

One source of evidence comes from a series of Negative Income Tax (NIT) experiments carried out in the United States from the late 1960's. The empirical results from these experiments have been surveyed by Robins (1985). The results indicate that participation elasticities are often above 0.5 and sometimes close to 1 for married women (secondary earners), single mothers, low-educated individuals, and the young. On the other hand, the participation decision of prime-age males was estimated to be fairly unresponsive to changes in incentives.

More recently, some countries have experimented with various 'in-work' benefit reforms for low income workers. Blundell (2001) describes the reforms and provides a survey of results from the experiences in the United States, the United Kingdom, and Canada. For the United States, Eissa and Liebman (1996) and Meyer and Rosenbaum (2001) document that the 1986 expansion of the EITC has had large effects on the labor force participation of single mothers. This was especially the case for single mothers with low education, where the Eissa-Liebman study implies an elasticity around 0.6.

Like the EITC, the recently implemented Working Families Tax Credit (WFTC) in the United Kingdom was designed to induce lone mothers from welfare into work. The study by Blundell et al. (2000) indicate that the reform was quite effective in achieving this goal. They find that the participation rate of single women with children increased by 2.2 percentage points ( 5 per cent). Another interesting source of evidence is provided by the Canadian Self Sufficiency Programme (SSP), which was structured very much like the EITC and WFTC. 
The advantage of the Canadian program lies in the fact that it is a randomized experiment rather than an actual policy reform, thereby providing an ideal setup to estimate labor supply behavior. A study by Card and Robins (1998) suggests that this experiment created a very large increase in labor market attachment. In fact, the treatment group almost doubled their participation rate over the control group.

The finding that tax incentives may have quite substantial effects on labor force participation is consistent with another stream of empirical literature estimating the effect of out-of-work benefits on unemployment. Krueger and Meyer (2002) survey the evidence from a number of OECD countries. They conclude that benefits raise the incidence and the duration of unemployment, and that the elasticity of lost work time with respect to benefits tend to be around one. Since the risk of unemployment is largest among low-skilled workers, this evidence also indicates that strong participation responses tend to be concentrated at the bottom of the wage distribution.

Although the literature on labor supply in anglo-saxon countries is extensive, there are many fewer studies on labor supply responses for continental European countries. An important objection to our method is that elasticities might be substantially smaller in the more rigid labor markets of continental Europe than in Anglo-saxon countries. Several recent studies suggest that this is not the case. A number of structural studies of the labor supply of married females are surveyed in Blundell and MaCurdy (1999, pp. 1649-1951). In general, these studies find substantial elasticities (between 0.5 and 1) for most countries (Germany, Netherlands, France, Italy, and Sweden) although they do not decompose the elasticity into participation versus hours of work on the job. Blundell (1995) surveys studies of labor market participation responses in OECD countries and suggests that elasticities for married women are substantial and similar across countries with values close to 1 (pp. 58-61).

Similarly, Van Soest (1995) and Van Soest et al. (2002) obtain substantial elasticities for females in the range 0.5 to 1 in a structural model for Netherlands. Most of those elasticities are due to substantial participation effects. Similarly, Aaberge et al. (1999) propose a structural estimation for Italy and find substantial participation elasticities for women (and much lower elasticities of hours of work conditional on working). Piketty (1998) analyzes the introduction in France in 1994 of an allowance for non-working wives with three or more children and finds convincing evidence of large participation effects, with elasticities in the range 0.6 to 1 for 
women with young children.

Thus, the evidence from structural estimation as well as direct policy change analysis suggests large participation elasticities for women across all European regions (Continental, Nordic and Southern Europe) with magnitudes similar to those obtained in the large literature on Anglo-Saxon countries. Thus, it is perhaps a reasonable first step to assume homogeneous elasticities of labor supply as we do in this analysis.

Since the empirical literature focuses on various demographic subgroups, it is not easy to calibrate elasticities across income deciles. Yet, from available evidence, it seems reasonable to conclude that participation elasticities are large, perhaps above 0.5 , for the groups in the lower part of the income distribution. Participation elasticities in the middle part of the distribution are likely to be substantially lower, while there is almost no responsiveness of labor force participation at the top of the distribution (see, e.g., Blundell, 1995). In our benchmark case, we will calibrate the average participation elasticity for the whole economy is equal to 0.2 but decreasing across deciles. ${ }^{21}$ We will also consider sensitivity analysis with higher and lower average participation elasticities. Finally, because the empirical literature shows that female labor supply tend to be more elastic than primary earners' labor supply, we will also present simulations where the participation elasticity is heterogeneous within deciles and concentrated among married women and lone parents only (with a zero participation elasticity for married men and singles with no children).

For the hours-of-work elasticity, we will assume that it is constant across income deciles (like, e.g., Diamond, 1998, and Saez, 2001). We will take an elasticity equal to 0.1 to be our baseline case, but will also consider values equal to 0 and $0.2 .^{22}$

To allow interested readers to compute efficiency measures using under the behavioral elasticity parameters of their choice, we are constructing an spreadsheet file incorporating the relevant simulation formulas. The file will also contain detailed EUROMOD results on the tax rates for each demographic and earnings group. It will be posted on the EUROMOD website and on the personal webpages of the authors.

\footnotetext{
${ }^{21}$ The elasticity is 0.4 for deciles 1 and 2, 0.3 for deciles 3 and 4, 0.2 for deciles 5 and 6, 0.1 for deciles 7 and 8 , and 0 for deciles 9 and 10 .

${ }^{22}$ A large literature for the United States has shown that very high income earners might be much more responsive to tax rates than middle or middle high income earners (see Saez, 2004 for a recent summary). However, this phenomenon is concentrated at the very top (top 1\%) and thus, for our purpose, this high-income elasticity should only increase slightly the overall intensive elasticity of the top deciles income earners.
} 


\subsection{Quantifying the Equity-Efficiency Trade-Off}

In this section, we simulate the impact of a demogrant welfare reform and a working poor welfare reform in EU countries. In order to do so, we combine the theory laid out in Section 2 with the EUROMOD tax and benefit calculations presented in Section 3.1, and setting labor supply elasticities as described in Section 3.2. Our evaluation of the two types of welfare reform focuses on economic efficiency and, most importantly, on the trade-off between efficiency and equality. The pure efficiency effect is measured in proportion of collected revenue and is found by calculating $-D$ from expressions (15) and (18). The number is the fraction of mechanical tax revenue that is lost due to behavioral responses. A negative value corresponds to an efficiency loss. The trade-off between efficiency and equality $(\Psi)$ is derived from formulas $(16)$ and (19). Recall from Section 2 that our measure of the trade-off gives the welfare cost to the rich of transferring one additional Euro to the poor (or the working poor).

We consider as our baseline case an hours-of-work elasticity equal to 0.1 and a participation elasticity for the aggregate economy equal to 0.2 in Panel A of Table 2. Panel A shows that the efficiency implications of welfare reform depend crucially on who is targeted by the reform, the poor or the working poor. Redistributing income to the poor by increasing the demogrant leads to efficiency losses in all countries, implying a trade-off between efficiency and equality above one. Although there is substantial variation across countries, the equity-efficiency trade-offs tend to be very unfavorable. The smallest trade-offs are found primarily in Southern Europe and Anglo-Saxon countries where taxes and benefits are relatively low. In Greece and Spain, for instance, a moderate $20 \%$ of the revenue raised by higher marginal tax rates on earnings is lost due to behavioral responses. This reduces the amount available as a transfer to the poor so that transferring 1 Euro to the poor would reduce the welfare of the losers from the reform by 1.52 Euros in Spain and 1.66 in Greece. In the United Kingdom, giving 1 Euro to low-wage earners and those out of work imposes a welfare cost on high-wage earners equal to 1.88 Euros. At the other extreme, we find the three Nordic countries, Denmark, Finland, and Sweden, where the generosity of existing welfare programs gives rise to large efficiency losses and where the trade-off is $25.25,6.17$ and 8.35, respectively. This implies that any additional redistribution in those countries would be extremely costly even for the moderate elasticities we are using. In between these extreme cases, we have a middle group of continental European 
countries like Belgium, Germany, France, and the Netherlands. In these countries, the welfare cost to the rich from transferring 1 Euro to the poor centers around 4 Euros.

A completely different picture emerges once we turn to the working poor policy. For all countries the loss of economic efficiency is now substantially lower. In fact, for Denmark, Ireland, France, Portugal, and Spain the policy would create an aggregate welfare gain, implying a trade-off which is lower than 1 . That is, it would cost less than 1 Euro for the rich to transfer 1 Euro to the working poor. For many other countries the working poor policy creates only small efficiency losses such that the trade-off is quite close to one. This applies to countries such as Austria, Greece, Luxembourg, Netherlands, and the United Kingdom. In these countries there is no significant trade-off between efficiency and equality when we consider redistribution from the rich to the working poor. Only in the case of Finland and Sweden does the working poor policy involve an unfavorable equity-efficiency trade-off. The in-work benefit reform does not work as well in these two countries mainly because of the extremely equal earnings distribution (see Figure 3). With a strongly compressed earnings distribution, the taxes most workers pay and the benefits they receive are of a very similar size so that they gain or loose only very small amounts. Hence the reform generates almost no redistribution per dollar of deadweight burden, thereby creating an unfavorable equity-efficiency trade-off (see the discussion in Section 2.4). ${ }^{23,24}$

Panel B of Table 2 reports the results in the case of a zero participation elasticity, the situation most previous studies have focused on. In contrast to Panel A, the demogrant and the working poor policies now produce exactly the same efficiency losses $-D$, but the demogrant policy produces a more favorable equity-efficiency trade-off as it spreads gains and losses more widely among groups, a point we discussed earlier. These results illustrate that it can be quite misleading to use the standard labor supply model to study welfare reform for low-income earners when participation elasticities are indeed significant.

To get a better grasp of the difference between the demogrant or working poor policies, notice from Figure 1 that countries with relatively high participation tax rates in the bottom

\footnotetext{
${ }^{23}$ In the extreme case of a perfectly equal earnings distribution, the in-work benefit reform would create deadweight burden with no gainers, hence creating an infinite trade-off ratio.

${ }^{24}$ The working poor policy is desirable in Denmark despite a compressed earnings distribution because participation tax rates are extremely high in this country (even relative to Finland and Sweden), especially in the bottom deciles where participation elasticities are also high. In the simulations, this effect strongly dominates the effect of a compressed earnings distribution.
} 
deciles, such as Denmark, Ireland, or France, tend to gain more by choosing a working poor policy rather than a demogrant policy. The working poor policy creates, ceteris paribus, higher incentives for participation in the labor force. Moreover, participation rises mainly at the bottom deciles where participation elasticities are large. If participation tax rates are very large at the bottom deciles, the increase in labor participation creates a large increase in government revenue (through reduced benefit expenditures and a higher tax take) and hence in economic efficiency. This may be seen more formally by noting from eq. (18) that

$$
\left(1-D_{d}\right) /\left(1-D_{w}\right)=1-\sum_{j=1}^{J} \frac{a_{j}}{1-a_{j}} \eta_{j} e_{j} .
$$

The participation elasticities $\left(\eta_{j}\right)$ are large at the bottom of the wage distribution while the employment shares $\left(e_{j}\right)$ are, by definition, equal to 0.1 for all deciles. Hence, the working poor policy has a relatively large effect on economic efficiency compared to the demogrant policy if participation tax rates $\left(a_{j}\right)$ are high at the bottom deciles. ${ }^{25}$

In order to provide an additional perspective of the results, Table 3 examines the size of average participation elasticities required in each country to make the working poor policy more attractive than the demogrant policy or attractive in absolute terms. ${ }^{26}$ Panel A displays the average participation elasticities for which the trade-off ratios are the same for both policies. These average elasticities are extremely low for most countries, typically around 0.05-0.1 and never above $0.2 .{ }^{27}$ If the social planner puts a higher value on the marginal consumption of non-working individuals than on the working poor (the standard assumption in the literature), then the demogrant policy is preferable to the working poor policy if the average participation elasticity is below the numbers displayed in Panel A. ${ }^{28}$

Panel B displays the average participation elasticities at which the working poor policy generates zero efficiency loss: At these elasticities, it would cost exactly 1 Euro for the rich to redistribute 1 Euro to the working poor. With a trade-off equal to one, since the working

\footnotetext{
${ }^{25}$ Similarly, shifting the profile of the participation elasticities so that the participation response is more concentrated in the bottom of the earnings distribution would make the working poor policy relatively more attractive.

${ }^{26}$ The profile of the participation elasticity is the same as in the benchmark case. The hours of work elasticity is always uniformly equal to 0.1 .

${ }^{27}$ They are highest in Italy (0.18), Finland (0.17), and Sweden (0.14) and at most 0.1 everywhere else.

${ }^{28} \mathrm{It}$ is conceivable, however, that a conservative government would value more at the margin consumption of the working poor (deemed "deserving") than the consumption of the unemployed (deemed "lazy"). In that case, having a participation elasticity above the numbers from Panel A would make the working poor policy more attractive.
} 
poor policy is a redistributive policy, it would be desirable under any redistributive social welfare criterion. The size of average participation elasticities ensuring this tend to remain in the moderate range (around 0.25) for most countries, and they are highest in the case of Italy at 0.45 . This suggests that the working poor policy would be desirable in its own right (independently of the demogrant policy) in a number of countries for realistic values of participation elasticities.

Finally, Panel C displays the average participation elasticities required to make the working poor policy a Pareto improvement. When the elasticity is higher than this critical value, the working poor policy is self financing: redistributing to the working poor induces so many non-working welfare recipients to take a job that the savings in welfare benefits, together with the additional tax revenue, fully finance the in-work benefit. As a result, there is no need to tax higher-income earners and everybody benefits from the policy. In most countries, the average participation elasticity required to be in that scenario are quite high (on average around 0.5). It is striking to note, however, that in some countries such as Belgium, France, Ireland or Sweden, average elasticities as low as 0.3 or 0.4 would be enough to generate a Pareto improvement. Denmark is the most extreme case where an elasticity as low as 0.2 (the value underlying our default scenario in Table 2) is enough to generate a Pareto improvement.

Taken together, the results from Table 3 suggest that low participation elasticities would be sufficient to make the working poor policy more desirable than traditional welfare, and that moderate participation elasticities would make the working poor policy attractive in its own right.

The sensitivity of the results with respect to the hours-of-work elasticity is analyzed in Table 4. The analysis indicates that the simulated effects on economic efficiency and equityefficiency trade-off are quite sensitive to the size of the hours-of-work elasticity. However, unlike the level of the participation elasticity, the hours-of-work elasticity has the same qualitative impact on the demogrant policy and the working poor policy. Hence, the relative effects of the two policies are less influenced by the size of the hours-of-work elasticity. A relatively high hours-of-work elasticity such as 0.2 in panel $\mathrm{C}$ makes the efficiency costs and the trade-off ratios of both the demogrant and working poor policies high. This illustrates once more that it is crucial to distinguish between the participation and the hours-of-work elasticity when evaluating tax and welfare reform. 
In Table 5, we explore how sensitive our results are to whether or not out-of-work individuals are in fact receiving unemployment benefits (see the discussion in Section 3.1). In Panel A, we repeat our benchmark scenario which includes unemployment benefits for the fraction of all out-of-work individuals entitled to receive them. In Panel B, we exclude unemployment benefits completely, and we replace them by minimum income benefits where such benefits are available. We note that the gap between the demogrant and the working poor policies narrows a little bit but the qualitative implications remain the same. As long as there are moderate participation elasticities, the current tax and benefits systems, even ignoring unemployment insurance, imply that the demogrant policy generates more deadweight burden and creates a less favorable equity-efficiency trade-off than the working benefits policy.

Finally, in Table 6, we consider the case where participation elasticities are heterogeneous within deciles among different demographic groups. In Panel A, we repeat the benchmark scenario while in Panel B, we assume that participation elasticities are concentrated among married women and lone parents and zero otherwise (married men and singles with no kids). ${ }^{29}$ In both Panels $\mathrm{A}$ and $\mathrm{B}$, the average intensive and extensive elasticities are 0.1 and 0.2 , respectively. Introducing heterogeneity in the elasticities has only modest effects on our efficiency and trade-off measures. The numbers for the working poor policy are very similar while the demogrant policy tend to look slightly better with heterogeneous elasticities. However, in all countries, the working poor policy continues to appear more favorable (and often much more favorable) than the demogrant policy suggesting that our results are indeed very robust to introducing heterogeneity in the elasticities across demographic groups.

\subsection{Majority Support and Distributional Effects}

Our results strongly suggest that, for most countries and for realistic labor supply elasticity assumptions, the working poor policy is more desirable than the demogrant policy on efficiency grounds. This raises two important questions. First, is the working poor policy more likely to be supported by a majority of self-interested voters. Second, what are the redistributive consequences of introducing the policy?

Columns (1) and (2) of Table 7 show the share of gainers for the demogrant and the

\footnotetext{
${ }^{29}$ More precisely, the participation elasticity both married women and lone parents is 0.9 in deciles 1 and 2 , 0.6 in deciles 3 and 4, 0.4 in deciles 5 and 6, 0.2 in deciles 7 and 8, and zero for deciles 9 and 10 .
} 
working poor policy, respectively, in the case of our benchmark case for elasticities (Table 2, Panel A). ${ }^{30}$ Taking the number of gainers as indicating support for the measure, we see that the demogrant policy would command a majority in Spain and Italy only. In most countries, especially in the Nordic ones with generous transfer policies, a large majority would instead favor rolling back the welfare state (a negative demogrant policy). By contrast, column (2) shows that, for most countries, the working poor policy would be supported by a majority. ${ }^{31}$ The reason for those results is again that the in-work benefit creates a low (or no) deadweight burden and therefore generates more gainers than losers.

The working poor policy hence appears to be economically efficient and also politically feasible. The last point we examine is the redistributive consequences of such a policy. The working poor policy benefits workers with low earnings at the expense of higher income earners (non-workers are left unaffected by the policy). However, the policy has been defined at the individual level, independent of total family income. Hence, the working poor policy provides the same benefit to a low income working lone parent and to a low income spouse married to a high income husband. Therefore, it is conceivable that the redistributive consequences of the working poor policy are actually much less attractive when total family income is taken into account. To investigate this point, columns (3) to (12) display the share of workers benefiting from the working poor policy in each family disposable income decile. ${ }^{32}$ Our results show that, even though some of the gainers are indeed in the top decile, the fraction of gainers is always highest in the bottom deciles. In other words, although some working spouses of highwage earners will gain from the reform, most of the gainers will be individuals with modest family incomes. Thus, the working poor policy also appears to be redistributing from high income families toward low income families on average. Finally, it is important to note that the redistributive properties of the working poor policy (or any other small tax/transfer change) are independent of the distribution of the behavioral responses. For example, the policy will have the same redistributive properties even if only wives with wealthy husbands are induced to work because of the policy and if lone parents are completely inelastic. What matters in the

\footnotetext{
${ }^{30}$ In the case of the working poor policy, the non-working population is excluded as it is unaffected by the policy.

${ }^{31}$ Only in Belgium, Finland, Germany, and Sweden would a majority be opposed to the introduction of a working poor policy.

${ }^{32}$ Hence, in our previous example, the lone parent is likely to be in the bottom deciles while the spouse of the high income husband is likely to be in the top deciles.
} 
analysis is the total revenue loss due to all behavioral responses, and the static redistributive properties of the policy.

\section{Discussion}

This paper has proposed an analysis of welfare reform in European countries using a simple static model of labor supply and the EUROMOD micro-simulation model. Following the findings of the empirical labor supply literature, we have modelled labor supply responses not just along the intensive margin (as done by most previous policy reform studies) but also along the extensive margin. Our analysis leads to quite definite and robust results. Due to the presence of significant labor supply responses along the extensive margin, expanding traditional welfare programs have very different implications than introducing in-work benefits. Increasing redistribution through traditional welfare can lead to significant negative labor supply responses along both the intensive and the extensive margins. Since existing transfer programs generate substantial tax rates at the bottom, these negative labor supply responses are very costly in terms of government revenue and efficiency. In fact, the welfare cost on highwage earners from redistributing one additional Euro to the poor is in the order of magnitude of 2 to 4 Euros for most countries. By contrast, in-work benefit reform generates positive labor supply responses along the extensive margin (along with a negative response along the intensive margin). As a result, the efficiency cost of redistribution through this type of reform is much smaller and sometimes very close to zero. In fact, in a number of countries, the welfare cost on higher-income individuals from redistributing one additional Euro to the working poor is very close to one Euro.

It needs to be emphasized, however, that the groups who benefit from redistribution in the two reforms are different. In the traditional welfare case, those who benefit the most are people with no earnings at all, presumably those who are the most in need of support. In the in-work benefit case, people with no earnings receive no additional support and redistribution benefits only the working poor. As a result, if the government had extreme redistributive tastes and put a much higher welfare weight on those with no incomes than on the working poor (such as in the case of a Rawlsian welfare criterion), it is possible that increasing traditional welfare would be more desirable than introducing in-work benefits. ${ }^{33}$

\footnotetext{
${ }^{33} \mathrm{By}$ contrast, if the government puts lower welfare weights on those with no earnings than on the working
} 
Our findings are in line with the recent developments in taxes and benefits in Europe. As we discussed above, since 1998 (the year upon which our analysis is based), a number of European countries have introduced in-work benefits. By 2003, eight of the fifteen countries in our sample had implemented in-work benefits programs. Except for Ireland and the United Kingdom, however, these in-work benefit programs are still modest in size with maximum annual benefits between 300 and 1000 Euros (see OECD, 2004, for the most recent and systematic description of these programs). Therefore, our "small reform" methodology and results should in principle provide a good approximation of the effect of introducing such programs. As illustrated by Blundell (2002) for the case of the extension of in-work benefits in 1999 in the United Kingdom, such prospective analysis should be supplemented by direct empirical analysis after the reform. The recent introduction of in-work benefits in several European countries offers a promising avenue to test our results empirically. Additional and more precise empirical results would be easy to incorporate into our model to improve the accuracy of our analysis.

Our simple labor supply model abstracts from a number of issues which we would like to discuss briefly. First, and perhaps most importantly, we have assumed that the labor market is perfectly competitive. This might be a poor approximation to European labor markets, where minimum wages tend to be substantial, and where wage rates are often the result of bargaining between unions and employers. Minimum wages prevent employers from paying wages which are below a defined minimum, thereby eliminating jobs with very low productivities and potentially creating involuntary unemployment among the low-skilled. Likewise, union bargaining models, efficiency wage models, and search models imply that a fraction of individuals become involuntary unemployed.

The effects of taxation in imperfect labor markets have been explored in a number of recent papers (see, e.g., the survey by Sørensen, 1997). The introduction of imperfections will not change the most important mechanisms at work in our analysis. Firstly, variation in aggregate employment is still the result of behavioral responses along the intensive and the extensive margins. For example, Sørensen (1999) considers optimal taxation in three different models of involuntary employment (unions, efficiency wages, and search) where both intensive and extensive responses are present. Secondly, in all imperfect labor market models,

poor, the case for in-work benefits would be even stronger. Conservative governments tend to hold the latter view: those not working may be seen as "lazy", whereas the working poor are seen as deserving. 
a reduction of average tax rates leads to higher employment, where the effect is channelled through lower equilibrium wages. Accordingly, a working poor policy would lead to increased job opportunities, while a demogrant policy would reduce the chances of finding a job. ${ }^{34}$

While the most important employment effects would survive the introduction of labor market imperfections, the welfare implications of changed labor force participation would be affected by the presence of involuntary unemployment. Following the introduction of in-work benefits, those who obtain jobs would experience a discrete (as opposed to an infinitesimal) increase in utility because some of them were previously involuntarily unemployed. This reinforces the positive effect of the working poor policy on welfare. Increasing traditional welfare programs, on the other hand, creates higher unemployment. To the extent that people lose their jobs involuntarily, the welfare loss is exacerbated relative to the case of voluntary unemployment. In conclusion, a model with labor market imperfections generating involuntary unemployment would most likely increase the attractiveness of redistributing to the working poor and reduce the attractiveness of increasing traditional welfare programs, thereby reinforcing the main conclusion of this paper.

Second, there might be issues related to the presence of segmented labor markets. A wellknown hypothesis is that labor markets tend to have a dual structure, being segmented into a perfectly competitive sector offering low-paying, low-productivity jobs and an imperfectly competitive sector offering high-paying, high-productivity jobs. Indeed, labor economists have gathered considerable evidence in favor of the dual labor market hypothesis (see, e.g., the survey by Saint-Paul, 1996, pp. 62-68). In the dual labor market model, there is a distortion in the allocation of employment in favor of the perfectly competitive sector offering low-paying jobs. As pointed out by Bulow and Summers (1986), this implies that the government ought to use industrial policy to shift resources away from the low-productivity sector. In the context of tax reform, Kleven and Sørensen (2003) show that such sectoral distortions tend to make policies aimed at the working poor less attractive, because they promote bad jobs at

\footnotetext{
${ }^{34}$ In one respect the imperfect labor market models do involve different comparative statics than the competitive model. This difference relates to the effect of changes in the marginal tax rate. A higher marginal tax rate (for a given value of the average tax rate) may lead to a lower equilibrium wage rate which, ceteris paribus, imply higher employment. At the same time, higher marginal tax rates give rise to lower working hours for those who are working as in the standard competitive model. However, the important point to note is that these effects would apply to both the demogrant and the working poor policies, since both types of reforms increase the marginal tax rate. The main difference between the reforms lies in their implications for the average effective tax rates at the bottom of the earnings distribution.
} 
the expense of good jobs. A policy which succeeds in increasing aggregate employment by promoting low-paying jobs may, in theory, reduce welfare as it creates a deterioration in the sectoral mix of employment.

Labor force participation may also generate externalities. Positive externalities of working would make the introduction of in-work benefits even more attractive relative to traditional welfare, while negative externalities would make in-work benefits less attractive. Some of these externalities take the form of fiscal externalities, where higher employment rates affect the demand for certain commodities that are initially taxed or subsidized by the government. For example, higher employment may generate more demand for child care, which would then create positive or negative externalities depending on whether this commodity carries a positive or negative tax rate (in the Nordic countries, for example, child care is heavily subsidized). Externalities could also come in the form of social externalities. Positive social externalities would be reduced crime (as working individuals have less need and time to resort to criminal activities), newly employed parents being better role models for their children (which could increase the incentives of children to do well at school, etc.). Negative externalities are also a possibility if working reduces the time that parents can devote to their children and therefore worsen the quality of parental education.

Finally, a large body of work in behavioral economics has shown that individuals are not always able to make the best decisions for themselves, especially when those decisions involve intertemporal trade-offs. In the case of labor supply, it is conceivable that some individuals may not perceive the full future benefits of starting to work, or procrastinate in the decision to leave welfare and start working. Such models with inconsistent time preferences generate so-called internalities (Herrnstein et al., 1993) that are conceptually close to externalities: an individual may not internalize fully the utility of future selves and hence decide to work too little today. As a result, in-work benefits may be desirable to induce people to work more and help correcting such internalities. 


\section{References}

Aaberge, Rolf, Ugo Colombino and Steinar Strøm (1999). "Labor Supply in Italy: An Empirical Analysis of Joint Household Decisions, with Taxes and Quantity Constraints." Journal of Applied Econometrics, 14, 403-422.

Ballard, Charles L. (1988). "The Marginal Efficiency Cost of Redistribution." American Economic Review 78(5), 1019-1033.

Blundell, Richard W. (1995). "The Impact of Taxation on Labor Force Participation and Labor Supply," Chapter 3, OECD Job Study: Taxation, Employment, and Unemployment, OECD: Paris.

Blundell, Richard W. (2001). "Evaluating the Labour Supply Responses to 'In-Work' Benefit Reforms for Low Income Workers," in Buti, Marco, Paolo Sestito and Hans Wijkander (eds.), Taxation, welfare and the crisis of unemployment in Europe. Cheltenham: Edward Elgar, $157-87$

Blundell, Richard W. (2002). "Welfare to Work: Which Policies Work and Why?" Keynes Lecture in Economics 2001.

Blundell, Richard W. and Thomas MaCurdy (1999). "Labor Supply: A Review of Alternative Approaches," in O. Ashenfelter and D. Card (eds.), Handbook of Labor Economics vol. 3A. Elsevier Science B.V.: Amsterdam.

Blundell, Richard W., Alan Duncan, Julian McCrae and Costas Meghir (2000). "The Labour Market Impact of the Working Families Tax Credit." Fiscal Studies 21(1), 75104.

Bourguignon, François and Amedeo Spadaro (2002a) "Redistribution and Labour Supply Incentives: An Application of the Optimal Tax Theory." Mimeo.

Bourguignon, François and Amedeo Spadaro (2002b) "Tax Benefit Revealed Social Preferences: Are Tax Authorities Non-Paretian?" Mimeo.

Browning, Edgar K. (1995). "Effects of the Earned Income Tax Credit on Income and Welfare." National Tax Journal 48(1), 23-43.

Browning, Edgar K. and William R. Johnson (1984). "The Trade-Off between Equality and Efficiency." Journal of Political Economy 92(2), 175-203.

Bulow, Jeremy I. and Lawrence H. Summers (1986). "A Theory of Dual Labor Markets 
with Application to Industrial Policy, Discrimination, and Keynesian Unemployment." Journal of Labor Economics 4(3), 376-414.

Card, David and Philip K. Robins (1998). "Do Financial Incentives Encourage Welfare Recipients to Work?" Research in Labor Economics 17(4), 1-56.

Cogan, John F. (1981). "Fixed Costs and Labor Supply." Econometrica 49(4), 945-963.

Dahlby, Bev (1998) "Progressive Taxation and the Social Marginal Cost of Public Funds." Journal of Public Economics, 67(1), 105-122.

Daveri, Francesco and Guido Tabellini (2000). "Unemployment, Growth and Taxation in Industrial Countries." Economic Policy 30, 47-88.

Diamond, Peter A. (1998). "Optimal Income Taxation: An Example with a U-Shaped Pattern of Optimal Marginal Tax Rates." American Economic Review 88(1), 83-95.

Eissa, Nada and Jeffrey B. Liebman (1996). "Labor Supply Response to the Earned Income Tax Credit." Quarterly Journal of Economics 111(2), 605-37.

Gruber, Jonathan, and David Wise (1999). Social Security and Retirement around the World. University of Chicago Press: Chicago.

Heckman, James (1993). "What Has Been Learned About Labor Supply in the Past Twenty Years?" American Economic Review Papers and Proceedings 83(2), 116-121.

Herrnstein, Richard J., George E. Loewenstein, Drazen Prelec, and William Vaughan Jr. (1993). "Utility maximization and melioration: Internalities in individual choice." Journal of Behavioral Decision Making, 6, 149-185.

Immervoll, Herwig (2004). "Average and marginal effective tax rates facing workers in the EU. A micro-level analyis of levels, distributions and driving factors." OECD Social, Employment and Migration Working Paper No. 19, OECD: Paris.

Immervoll, Herwig, and Cathal O'Donoghue (2003). "Employment transitions in 13 European countries. Levels, distributions and determining Factors of net replacement rates." CESifo Working Paper No. 1091, CESifo: Munich.

Kleven, Henrik J. and Claus T. Kreiner (2003). "The Marginal Cost of Public Funds in OECD Countries: Hours of Work Versus Labor Force Participation.” CESifo Working Paper no. 935 .

Kleven, Henrik J. and Peter B. Sørensen (2003). "Labour Tax Reform, The Good Jobs and The Bad Jobs." Forthcoming in Scandinavian Journal of Economics. 
Krueger, Alan B. and B.D. Meyer (2002). "Labor Supply Effects of Social Insurance," in Alan J. Auerbach and Martin Feldstein (eds.), Handbook of Public Economics, vol. 4. Amsterdam: North-Holland.

Liebman, Jeffrey (2002). "The Optimal Design of the Earned Income Tax Credit," in Bruce Meyer and Douglas Hotz-Eakin (eds.), Making Work Pay: The Earned Income Tax Credit and Its Impact on America's Families, New-York: Russell Sage Foundation.

Mendoza, E.G., A. Razin, and L.L. Tesar (1994). "Effective Tax Rates in Macroeconomics. Cross-Country Estimates of Tax Rates on Factor Incomes and Consumption." Journal of Monetary Economics 34, 297-323.

Meyer, Bruce D. and Dan T. Rosenbaum (2001). "Welfare, the Earned Income Tax Credit, and the Labor Supply of Single Mothers." Quarterly Journal of Economics 116(3), 1063-1114.

Mirrlees, James A. (1971) "An Exploration in the Theory of Optimal Income Taxation." Review of Economic studies, 38, 175-208.

Mroz, Thomas A. (1987). "The Sensitivity of an Empirical Model of Married Women's Hours of Work to Economic and Statistical Assumptions." Econometrica 55(4), 765-799.

Murray, Charles (1984). Loosing Ground: American Social Policy 1950-1980. New York: Basic Books.

OECD (1999) Benefits Systems and Work Incentives, OECD: Paris.

OECD (2002) Revenue Statistics: 1965-2001, OECD: Paris.

OECD (2003) National Accounts, Volume II 1990-2001, OECD: Paris.

OECD (2003) Labor Force Statistics, OECD: Paris.

OECD (2004) Benefits and Wages, OECD: Paris.

Pencavel, John H. (1986). "Labor Supply of Men: A Survey," in O. Ashenfelter and R. Layard (eds), Handbook of Labor Economics, vol. 1. Amsterdam: North-Holland.

Piketty, Thomas (1998). "L'Impact des Incitations Financières au Travail sur les Comportements Individuels: Une Estimation pour le cas Français." Economie et Prevision, 132-133, $1-35$.

Robins, Philip K. (1985). "A Comparison of the Labor Supply Findings from the Four Negative Income Tax Experiments." Journal of Human Resources 20(4), 567-82.

Saez, Emmanuel (2001). "Using Elasticities to Derive Optimal Income Tax Rates." Review 
of Economic Studies 68(1), 205-229.

Saez, Emmanuel (2002). "Optimal Income Transfer Programs: Intensive Versus Extensive Labor Supply Responses." Quarterly Journal of Economics 117(3), 1039-1073.

Saez, Emmanuel (2004). "Reported Incomes and Marginal Tax Rates, 1960-2000: Evidence and Policy Implications," in J. Poterba, ed., Tax Policy and the Economy, Volume 18, Cambridge: MIT Press.

Saint-Paul, Gilles (1996). Dual Labour Markets: A Macroeconomic Perspective. MIT Press, Cambridge, Massachusetts.

Sørensen, Peter B. (1997). "Public Finance Solutions to the European Unemployment Problem?" Economic Policy 25, 223-264.

Sørensen, Peter B. (1999). "Optimal Tax Progressivity in Imperfect Labour Markets." Labour Economics 6, 435-452.

Sutherland, Holly (2001). "Final Report EUROMOD: An Integrated European Benefit-Tax Model." EUROMOD Working Paper No. EM9/01.

Triest, Robert K. (1990). "The Effect of Income Taxation on Labor Supply in the United States." Journal of Human Resources 25(3), 491-516.

Triest, Robert K. (1994). "The Efficiency Cost of Increased Progressivity," in Joel Slemrod (ed.), Tax Progressivity and Income Inequality. Cambridge: Cambridge University Press.

Van Soest, A. (1995). "Discrete Choice Models of Family Labor Supply." Journal of Human Resources 30, 63-88.

Van Soest, A., M. Das, and X. Gong (2002). "A Structural Labor Supply Model with Flexible Preferences." Journal of Econometrics 107, 345-374. 
Table 1: Total social benefits as a percentage of disposable income by deciles in 1998

\begin{tabular}{|c|c|c|c|c|c|c|c|c|c|c|c|c|c|c|c|}
\hline Decile group & Austria & Belgium & Denmark & Finland & France & Germany & Greece & Ireland & Italy & $\begin{array}{l}\text { Luxem- } \\
\text { bourg }\end{array}$ & $\begin{array}{l}\text { Nether- } \\
\text { lands }\end{array}$ & Portugal & Spain & Sweden & $\begin{array}{l}\text { United } \\
\text { Kingdom }\end{array}$ \\
\hline 1 & 42.3 & 69.3 & 65.4 & 74.0 & 49.2 & 72.6 & 29.0 & 94.5 & 38.0 & 41.2 & 67.6 & 55.0 & 48.2 & 63.6 & 83.2 \\
\hline 2 & 31.6 & 53.3 & 62.8 & 64.3 & 38.7 & 45.7 & 27.4 & 74.2 & 37.9 & 33.4 & 49.2 & 28.8 & 35.3 & 80.4 & 67.9 \\
\hline 3 & 27.5 & 31.5 & 69.5 & 55.7 & 29.2 & 28.4 & 24.2 & 63.3 & 23.6 & 29.5 & 33.2 & 26.0 & 29.1 & 75.9 & 52.7 \\
\hline 4 & 27.6 & 32.1 & 41.1 & 43.2 & 23.0 & 23.8 & 15.4 & 42.6 & 25.6 & 25.8 & 19.7 & 19.2 & 28.5 & 51.4 & 31.6 \\
\hline 5 & 22.3 & 26.2 & 27.1 & 39.5 & 20.2 & 17.9 & 12.2 & 24.3 & 20.9 & 23.9 & 19.4 & 15.9 & 21.1 & 32.2 & 22.6 \\
\hline 6 & 17.0 & 23.9 & 25.6 & 34.7 & 18.2 & 15.1 & 12.4 & 16.3 & 20.6 & 23.4 & 12.6 & 11.8 & 15.6 & 23.7 & 12.5 \\
\hline 7 & 19.5 & 21.9 & 17.1 & 29.2 & 14.9 & 11.0 & 18.5 & 10.9 & 20.6 & 16.1 & 9.6 & 10.8 & 15.1 & 20.6 & 8.1 \\
\hline 8 & 17.3 & 15.0 & 13.3 & 25.0 & 10.8 & 9.4 & 8.4 & 8.5 & 20.0 & 13.6 & 6.1 & 14.2 & 14.6 & 17.4 & 6.4 \\
\hline 9 & 14.9 & 12.0 & 10.3 & 20.5 & 10.5 & 7.0 & 10.2 & 5.1 & 16.0 & 12.1 & 7.0 & 8.6 & 10.1 & 13.7 & 3.3 \\
\hline 10 & 16.7 & 10.2 & 4.3 & 13.1 & 8.1 & 4.5 & 6.5 & 1.9 & 12.5 & 7.0 & 4.2 & 8.6 & 5.8 & 6.3 & 1.6 \\
\hline Total & 20.0 & 21.2 & 20.9 & 30.1 & 16.4 & 15.1 & 11.9 & 15.7 & 19.0 & 17.1 & 13.9 & 13.1 & 15.3 & 26.0 & 12.9 \\
\hline
\end{tabular}

Source: EUROMOD tax and benefit calculations.

Note: Decile groups are for per-capita household disposable income. The "modified OECD" equivalence scale is used for computing per-capita figures (with weights 1 for the first adult, 0.5 for further adults and 0.3 for children aged under 14). Working age is 18-59. The table shows, for working age individuals, the sum total of per-capita social benefits as a percentage of the sum total of per-capita disposable income.

Disposable income is current cash market income plus cash social benefits minus taxes minus own social insurance contributions. 
Table 2: Welfare effects from tax reform with and without participation responses

\section{Panel A}

Benchmark scenario $\eta=0.2$ (on average) and $\varepsilon=0.1$

Demogrant Policy W Working Poor Policy

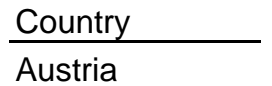

Belgium

Denmark

Finland

France

Germany

Greece

Ireland

Italy

Luxembourg

Netherlands

Portugal

Spain

Sweden

United Kingdom

\begin{tabular}{cc} 
Efficiency & Trade-Off \\
\hline-0.38 & 3.04
\end{tabular}

$-0.57$

$-0.82$

$-0.58$

$-0.51$

$-0.50$

$-0.21$

$-0.39$

$-0.32$

$-0.26$

$-0.36$

$-0.29$

$-0.19$

$-0.62$

$-0.22$

\subsection{3}

25.25

6.17

4.32

4.38

1.66

2.73

2.07

1.98

2.88

2.34

1.52

8.35

1.88

\begin{tabular}{cc} 
Efficiency & Trade-Off \\
\hline-0.08 & 1.50
\end{tabular}

$-0.14 \quad 1.93$

$1.65 \quad 0.00$

$-0.21 \quad 4.93$

$0.07 \quad 0.76$

$-0.12 \quad 1.89$

$-0.05 \quad 1.29$

$0.26 \quad 0.39$

$-0.12 \quad 1.96$

$-0.06 \quad 1.29$

$-0.07 \quad 1.37$

$0.00 \quad 0.99$

$0.00 \quad 0.99$

$-0.17 \quad 4.36$

$-0.01 \quad 1.06$

\section{Panel B}

No participation responses

$\eta=0$ and $\varepsilon=0.1$

Demogrant Policy Working Poor Policy

\begin{tabular}{ccccc} 
Efficiency & Trade-Off & & Efficiency & Trade-Off \\
\cline { 1 - 2 } \cline { 5 - 6 }-0.16 & 1.57 & & -0.16 & 2.16 \\
-0.25 & 1.87 & & -0.25 & 3.45 \\
-0.23 & 2.31 & & -0.23 & 4.75
\end{tabular}

$\begin{array}{llll}-0.24 & 2.11 & -0.24 & 6.32\end{array}$

$\begin{array}{llll}-0.17 & 1.61 & -0.17 & 2.39\end{array}$

$\begin{array}{llll}-0.19 & 1.72 & -0.19 & 2.67\end{array}$

$\begin{array}{llll}-0.10 & 1.26 & -0.10 & 1.59\end{array}$

$\begin{array}{llll}-0.14 & 1.42 & -0.14 & 1.82\end{array}$

$\begin{array}{llll}-0.16 & 1.43 & -0.16 & 2.62\end{array}$

$\begin{array}{llll}-0.12 & 1.38 & -0.12 & 1.71\end{array}$

$\begin{array}{llll}-0.15 & 1.56 & -0.15 & 2.10\end{array}$

$\begin{array}{llll}-0.13 & 1.44 & -0.13 & 1.68\end{array}$

$\begin{array}{llll}-0.07 & 1.16 & -0.07 & 1.34\end{array}$

$\begin{array}{llll}-0.22 & 2.23 & -0.22 & 7.48\end{array}$

$\begin{array}{llll}-0.09 & 1.30 & -0.09 & 1.48\end{array}$

Source: Authors' own simulations based on EUROMOD tax and benefit calculations.

Notes:

Efficiency denotes the marginal efficiency cost of the extra-tax used to finance the extra welfare benefits (a negative number is an efficiency loss).

Trade-off denotes the ratio of the welfare loss of losers to the welfare gains of gainers from the reform.

$\eta$ denotes the participation elasticity, and $\varepsilon$ denotes the hours-of-work elasticity which is assumed constant across deciles.

In the benchmark scenario $\eta=0.4$ in deciles 1 and $2, \eta=0.3$ in deciles 3 and $4, \eta=0.2$ in deciles 5 and $6, \eta=0.1$ in deciles 7 and $8, \eta=0$ in deciles 9 and 10 .

In the scenario without participation responses, $\eta=0$ in all deciles.

The tax and benefits computations include a fraction of unemployment benefits equal to the ratio of beneficiaries to those non-working 
Table 3: Critical values for the average participation elasticity

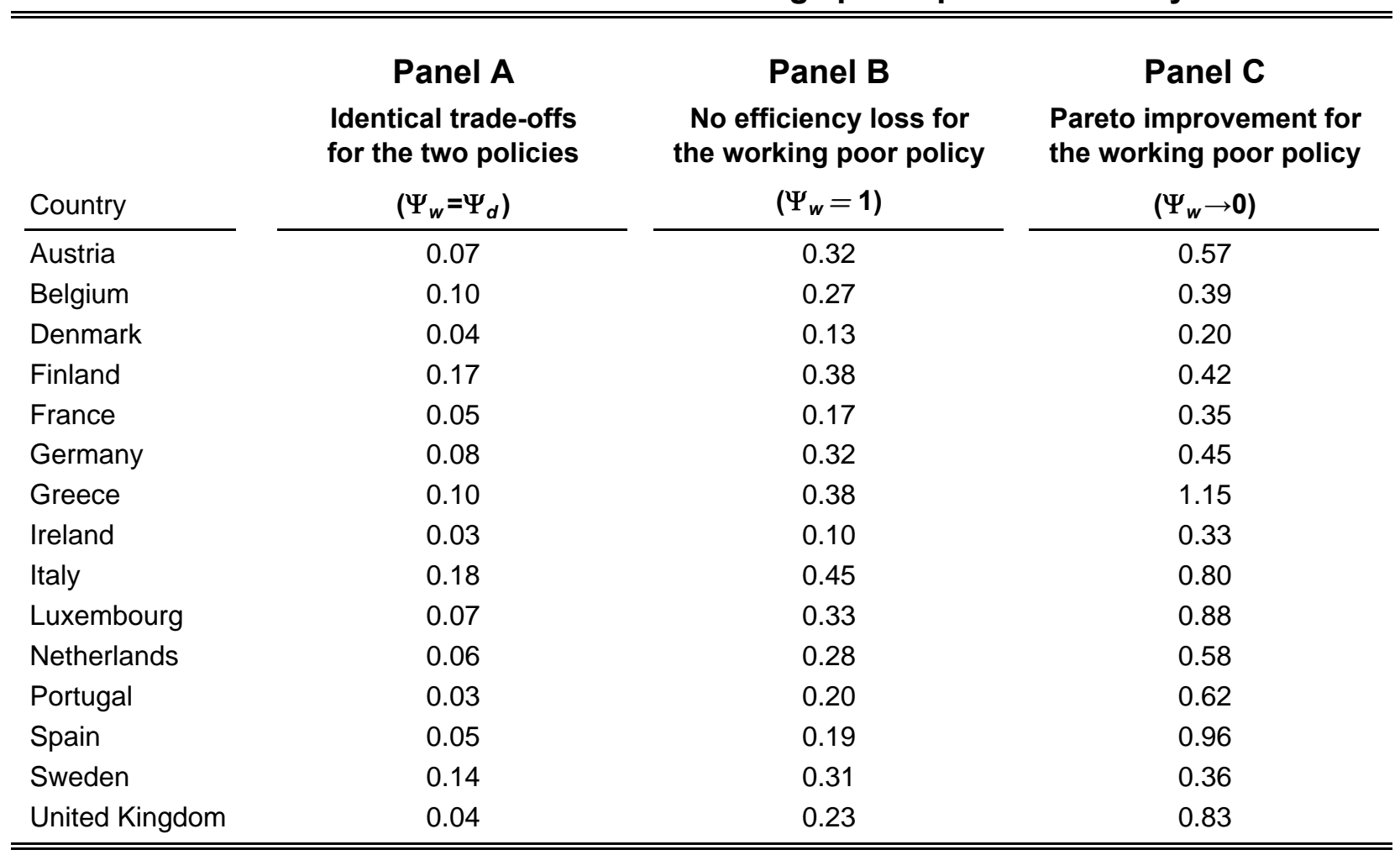

Source: Authors' own simulations based on EUROMOD tax and benefit calculations.

Notes:

In Panel A, if the average participation elasticity is above (below) the threshold in the table, the equity-efficiency trade-off is lower in the working poor policy (demogrant policy).

In Panel B, if the average participation elasticity is above the threshold in the table, redistribution through a working poor policy generates an efficiency gain.

In Panel C, if the average participation elasticity is above the threshold in the table, redistribution through a working poor policy generates a Pareto improvement.

The hours-of-work elasticity $\varepsilon$ equals 0.1 across all deciles.

All simulations have the same profile for the participation elasticity as used in the benchmark scenario: $\eta=2^{*} \eta^{\text {avg. }}$ in deciles 1 and $2, \eta=1.5^{\star} \eta^{\text {avg. }}$ in deciles 3 and $4, \eta=\eta^{\text {avg. }}$ in deciles 5 and $6, \eta=0.5^{\star} \eta^{\text {avg. }}$ in deciles 7 and 8 , and $\eta=0$ in deciles 9 and 10, where $\eta^{\text {avg. }}$ is the average participation elasticity over all the deciles. 


\section{Panel A}

No hours responses $\eta=0.2$ (on average) and $\varepsilon=0$

Demogrant Policy Working Poor Policy

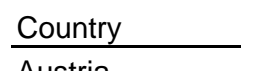

Efficiency Trade-Off

Austria

Belgium

Denmark

Finland

France

Germany

Greece

Ireland

Italy

Luxembourg

Netherlands

Portugal

Spain

Sweden

United Kingdom
Panel B

Benchmark scenario

$\eta=0.2$ (on average) and $\varepsilon=0.1$

\begin{tabular}{ccccc}
\multicolumn{2}{c}{ Demogrant Policy } & & \multicolumn{2}{c}{ Working Poor Policy } \\
\cline { 5 - 6 } Efficiency & Trade-Off & & Efficiency & Trade-Off \\
\cline { 1 - 2 } \cline { 5 - 6 }-0.38 & 3.04 & & -0.08 & 1.50 \\
-0.57 & 4.83 & & -0.14 & 1.93 \\
-0.82 & 25.25 & & 1.65 & 0.00 \\
-0.58 & 6.17 & & -0.21 & 4.93 \\
-0.51 & 4.32 & & 0.07 & 0.76 \\
-0.50 & 4.38 & & -0.12 & 1.89 \\
-0.21 & 1.66 & & -0.05 & 1.29 \\
-0.39 & 2.73 & & 0.26 & 0.39 \\
-0.32 & 2.07 & & -0.12 & 1.96 \\
-0.26 & 1.98 & & -0.06 & 1.29 \\
-0.36 & 2.88 & & -0.07 & 1.37 \\
-0.29 & 2.34 & & 0.00 & 0.99 \\
-0.19 & 1.52 & & 0.00 & 0.99 \\
-0.62 & 8.35 & & -0.17 & 4.36 \\
-0.22 & 1.88 & & -0.01 & 1.06
\end{tabular}

Panel C

Large hours responses

$\eta=0.2$ (on average) and $\varepsilon=0.2$

\begin{tabular}{|c|c|c|c|}
\hline \multicolumn{2}{|c|}{ Demogrant Policy } & \multicolumn{2}{|c|}{ Working Poor Policy } \\
\hline Efficiency & Trade-Off & Efficiency & Trade-Off \\
\hline-0.53 & 5.03 & -0.31 & 5.00 \\
\hline-0.82 & 14.78 & -0.63 & 36.55 \\
\hline \multicolumn{2}{|c|}{---- No Gainers ---- } & \multicolumn{2}{|c|}{---- No Gainers ---- } \\
\hline-0.82 & 17.63 & \multicolumn{2}{|c|}{---- No Gainers ---- } \\
\hline-0.68 & 8.20 & -0.31 & 5.66 \\
\hline-0.69 & 9.17 & -0.46 & 12.20 \\
\hline-0.30 & 2.13 & -0.17 & 2.36 \\
\hline-0.53 & 4.18 & -0.03 & 1.12 \\
\hline-0.49 & 3.16 & -0.33 & 8.50 \\
\hline-0.38 & 2.82 & -0.22 & 2.71 \\
\hline-0.51 & 4.75 & -0.29 & 4.20 \\
\hline-0.42 & 3.53 & -0.18 & 2.12 \\
\hline-0.25 & 1.79 & -0.08 & 1.43 \\
\hline-0.84 & 24.15 & \multicolumn{2}{|c|}{---- No Gainers ---- } \\
\hline-0.32 & 2.49 & -0.13 & 1.76 \\
\hline
\end{tabular}

Source: Authors' own simulations based on EUROMOD tax and benefit calculations.

$$
\text { Notes: }
$$

Efficiency denotes the marginal efficiency cost of the extra-tax used to finance the extra welfare benefits (a negative number is an efficiency loss)

Trade-off denotes the ratio of the welfare loss of losers to the welfare gains of gainers from the reform.

$\eta$ denotes the participation elasticity, and $\varepsilon$ denotes the hours-of-work elasticity which is assumed constant across deciles.

In all scenarios, $\eta=0.4$ in deciles 1 and $2, \eta=0.3$ in deciles 3 and $4, \eta=0.2$ in deciles 5 and $6, \eta=0.1$ in deciles 7 and $8, \eta=0$ in deciles 9 and 10 .

The tax and benefits computations include a fraction of unemployment benefits equal to the ratio of beneficiaries to those non-working. 
Table 5: Welfare effects from tax reform when excluding unemployment benefits

\begin{tabular}{|c|c|c|c|c|c|c|c|c|}
\hline \multirow[b]{4}{*}{ Country } & \multicolumn{4}{|c|}{ Panel A } & \multicolumn{4}{|c|}{ Panel B } \\
\hline & \multicolumn{4}{|c|}{ Benchmark scenario with benefits } & \multicolumn{4}{|c|}{ Benchmark scenario without benefits } \\
\hline & \multicolumn{2}{|c|}{ Demogrant Policy } & \multicolumn{2}{|c|}{ Working Poor Policy } & \multicolumn{2}{|c|}{ Demogrant Policy } & \multicolumn{2}{|c|}{ Working Poor Policy } \\
\hline & Efficiency & Trade-Off & Efficiency & Trade-Off & Efficiency & Trade-Off & Efficiency & Trade-Off \\
\hline Austria & -0.38 & 3.04 & -0.08 & 1.50 & -0.36 & 2.85 & -0.09 & 1.56 \\
\hline Belgium & -0.57 & 4.83 & -0.14 & 1.93 & -0.52 & 4.03 & -0.18 & 2.41 \\
\hline Denmark & -0.82 & 25.25 & 1.65 & 0.00 & -0.73 & 15.11 & 0.20 & 0.36 \\
\hline Finland & -0.58 & 6.17 & -0.21 & 4.93 & -0.51 & 4.93 & -0.22 & 5.43 \\
\hline France & -0.51 & 4.32 & 0.07 & 0.76 & -0.41 & 3.18 & -0.05 & 1.23 \\
\hline Germany & -0.50 & 4.38 & -0.12 & 1.89 & -0.48 & 4.14 & -0.13 & 1.95 \\
\hline Greece & -0.21 & 1.66 & -0.05 & 1.29 & -0.20 & 1.62 & -0.06 & 1.33 \\
\hline Ireland & -0.39 & 2.73 & 0.26 & 0.39 & -0.38 & 2.70 & 0.24 & 0.41 \\
\hline Italy & -0.32 & 2.07 & -0.12 & 1.96 & -0.32 & 2.05 & -0.12 & 1.98 \\
\hline Luxembourg & -0.26 & 1.98 & -0.06 & 1.29 & -0.25 & 1.95 & -0.07 & 1.31 \\
\hline Netherlands & -0.36 & 2.88 & -0.07 & 1.37 & -0.34 & 2.70 & -0.08 & 1.47 \\
\hline Portugal & -0.29 & 2.34 & 0.00 & 0.99 & -0.28 & 2.29 & -0.01 & 1.04 \\
\hline Spain & -0.19 & 1.52 & 0.00 & 0.99 & -0.15 & 1.39 & -0.03 & 1.12 \\
\hline Sweden & -0.62 & 8.35 & -0.17 & 4.36 & -0.57 & 6.93 & -0.18 & 4.98 \\
\hline United Kingdom & -0.22 & 1.88 & -0.01 & 1.06 & -0.22 & 1.87 & -0.02 & 1.08 \\
\hline
\end{tabular}

Source: Authors' own simulations based on EUROMOD tax and benefit calculations.

Notes:

Efficiency denotes the marginal efficiency cost of the extra-tax used to finance the extra welfare benefits (a negative number is an efficiency loss).

Trade-off denotes the ratio of the welfare loss of losers to the welfare gains of gainers from the reform.

The elasticities are the same in the two scenarios. The hours-of-work elasticity, $\varepsilon$, is equal to 0.1 across all deciles. The participation elasticities are equal to

0.2 on average. $\eta=0.4$ in deciles 1 and $2, \eta=0.3$ in deciles 3 and $4, \eta=0.2$ in deciles 5 and $6, \eta=0.1$ in deciles 7 and 8 , and $\eta=0$ in deciles 9 and 10 .

In the first scenario, the tax and benefits computations include a fraction of unemployment benefits equal to the ratio of beneficiaries to those non-working. In the second

scenario, the computations exclude completely unemployment benefits. 
Table 6: Welfare effects from tax reform where the participation elasticities are concentrated on married women and lone parents

\begin{tabular}{|c|c|c|c|c|c|c|c|c|}
\hline \multirow[b]{3}{*}{ Country } & \multicolumn{4}{|c|}{$\begin{array}{c}\text { Panel A } \\
\text { Benchmark scenario } \\
\text { Participation elasticities vary only with income }\end{array}$} & \multicolumn{4}{|c|}{$\begin{array}{c}\text { Panel B } \\
\text { Heterogeneity in participation elasticities } \\
\text { PE conc. on married women and lone parents }\end{array}$} \\
\hline & \multicolumn{2}{|c|}{ Demogrant Policy } & \multicolumn{2}{|c|}{ Working Poor Policy } & \multicolumn{2}{|c|}{ Demogrant Policy } & \multicolumn{2}{|c|}{ Working Poor Policy } \\
\hline & Efficiency & Trade-Off & Efficiency & Trade-Off & Efficiency & Trade-Off & Efficiency & Trade-Off \\
\hline Austria & -0.38 & 3.04 & -0.08 & 1.50 & -0.29 & 2.31 & -0.05 & 1.26 \\
\hline Belgium & -0.57 & 4.83 & -0.14 & 1.93 & -0.51 & 3.98 & -0.03 & 1.15 \\
\hline Denmark & -0.82 & 25.25 & 1.65 & 0.00 & -0.84 & 29.09 & \multicolumn{2}{|c|}{---- No Losers ---- } \\
\hline Finland & -0.58 & 6.17 & -0.21 & 4.93 & -0.46 & 4.10 & -0.20 & 4.65 \\
\hline France & -0.51 & 4.32 & 0.07 & 0.76 & -0.39 & 3.01 & -0.02 & 1.12 \\
\hline Germany & -0.50 & 4.38 & -0.12 & 1.89 & -0.42 & 3.41 & -0.07 & 1.40 \\
\hline Greece & -0.21 & 1.66 & -0.05 & 1.29 & -0.16 & 1.49 & -0.06 & 1.36 \\
\hline Ireland & -0.39 & 2.73 & 0.26 & 0.39 & -0.27 & 1.97 & 0.02 & 0.91 \\
\hline Italy & -0.32 & 2.07 & -0.12 & 1.96 & -0.27 & 1.82 & -0.11 & 1.84 \\
\hline Luxembourg & -0.26 & 1.98 & -0.06 & 1.29 & -0.20 & 1.69 & -0.06 & 1.28 \\
\hline Netherlands & -0.36 & 2.88 & -0.07 & 1.37 & -0.29 & 2.30 & 0.02 & 0.92 \\
\hline Portugal & -0.29 & 2.34 & 0.00 & 0.99 & -0.25 & 2.09 & -0.01 & 1.03 \\
\hline Spain & -0.19 & 1.52 & 0.00 & 0.99 & -0.14 & 1.36 & 0.00 & 1.02 \\
\hline Sweden & -0.62 & 8.35 & -0.17 & 4.36 & -0.42 & 4.30 & -0.20 & 6.21 \\
\hline United Kingdom & -0.22 & 1.88 & -0.01 & 1.06 & -0.18 & 1.64 & 0.00 & 1.02 \\
\hline
\end{tabular}

Source: Authors' own simulations based on EUROMOD tax and benefit calculations.

Notes:

Efficiency denotes the marginal efficiency cost of the extra-tax used to finance the extra welfare benefits (a negative number is an efficiency loss).

Trade-off denotes the ratio of the welfare loss of losers to the welfare gains of gainers from the reform.

In the benchmark scenario, the participation elasticities are as follows: $\eta=0.4$ in deciles 1 and $2, \eta=0.3$ in deciles 3 and $4, \eta=0.2$ in deciles 5 and $6, \eta=0.1$ in deciles 7 and 8 , and $\eta=0$ in deciles 9 and 10 .

In the heterogeneity scenario, the participation elasticities are as follows: For lone parents and married women, $\eta=0.9$ in deciles 1 and $2, \eta=0.6$ in deciles 3 and 4 , $\eta=0.4$ in deciles 5 and $6, \eta=0.2$ in deciles 7 and $8, \eta=0$ in deciles 9 and 10. For all other groups (singles and married men), the participation elasticities are zero. In both scenarios, the hours-of-work elasticity, $\varepsilon$, equals 0.1 in all deciles.

The tax and benefits computations include a fraction of Unemployment Benefits equal to the ratio of beneficiaries to those non-working. 
Table 7: Majority support and redistributive consequences

\begin{tabular}{|c|c|c|c|c|c|c|c|c|c|c|c|c|}
\hline \multirow[b]{3}{*}{ Country } & \multirow{3}{*}{$\begin{array}{c}\text { Demogrant policy } \\
\text { Share of popu- } \\
\text { lation gaining } \\
(1)\end{array}$} & \multicolumn{11}{|c|}{ Working poor policy } \\
\hline & & \multirow{2}{*}{$\begin{array}{l}\text { Share of em- } \\
\text { ployed gaining } \\
\text { (2) }\end{array}$} & \multicolumn{10}{|c|}{ Share of gainers across family income deciles } \\
\hline & & & $\begin{array}{l}\text { First } \\
(3) \\
\end{array}$ & $\begin{array}{c}\text { Second } \\
(4)\end{array}$ & $\begin{array}{c}\text { Third } \\
\text { (5) }\end{array}$ & $\begin{array}{c}\text { Fourth } \\
(6)\end{array}$ & $\begin{array}{c}\text { Fifth } \\
(7) \\
\end{array}$ & $\begin{array}{l}\text { Sixth } \\
(8) \\
\end{array}$ & $\begin{array}{c}\text { Seventh } \\
(9)\end{array}$ & $\begin{array}{l}\text { Eight } \\
(10) \\
\end{array}$ & $\begin{array}{l}\text { Ninth } \\
(11) \\
\end{array}$ & $\begin{array}{l}\text { Tenth } \\
(12) \\
\end{array}$ \\
\hline Austria & 0.37 & 0.50 & 0.85 & 0.63 & 0.65 & 0.67 & 0.51 & 0.48 & 0.53 & 0.30 & 0.24 & 0.15 \\
\hline Belgium & 0.39 & 0.49 & 0.92 & 0.76 & 0.68 & 0.59 & 0.58 & 0.43 & 0.33 & 0.31 & 0.17 & 0.15 \\
\hline Denmark & 0.19 & 1.00 & 1.00 & 1.00 & 1.00 & 1.00 & 1.00 & 1.00 & 1.00 & 1.00 & 1.00 & 1.00 \\
\hline Finland & 0.27 & 0.40 & 0.78 & 0.72 & 0.53 & 0.37 & 0.33 & 0.38 & 0.32 & 0.27 & 0.18 & 0.11 \\
\hline France & 0.37 & 0.70 & 0.99 & 0.93 & 0.91 & 0.89 & 0.84 & 0.77 & 0.60 & 0.49 & 0.36 & 0.20 \\
\hline Germany & 0.34 & 0.40 & 0.85 & 0.63 & 0.63 & 0.41 & 0.34 & 0.35 & 0.31 & 0.19 & 0.20 & 0.13 \\
\hline Greece & 0.48 & 0.60 & 0.98 & 0.76 & 0.56 & 0.66 & 0.61 & 0.67 & 0.58 & 0.50 & 0.42 & 0.25 \\
\hline Ireland & 0.46 & 0.72 & 0.99 & 0.86 & 0.84 & 0.81 & 0.77 & 0.73 & 0.68 & 0.60 & 0.51 & 0.37 \\
\hline Italy & 0.50 & 0.50 & 0.84 & 0.59 & 0.61 & 0.59 & 0.57 & 0.57 & 0.43 & 0.27 & 0.31 & 0.16 \\
\hline Luxembourg & 0.45 & 0.60 & 1.00 & 0.93 & 0.78 & 0.79 & 0.68 & 0.54 & 0.53 & 0.41 & 0.19 & 0.15 \\
\hline Netherlands & 0.39 & 0.50 & 0.73 & 0.61 & 0.57 & 0.60 & 0.62 & 0.49 & 0.43 & 0.46 & 0.30 & 0.20 \\
\hline Portugal & 0.40 & 0.70 & 0.99 & 0.93 & 0.89 & 0.80 & 0.86 & 0.78 & 0.68 & 0.63 & 0.32 & 0.10 \\
\hline Spain & 0.53 & 0.59 & 0.97 & 0.83 & 0.67 & 0.69 & 0.63 & 0.63 & 0.57 & 0.47 & 0.25 & 0.12 \\
\hline Sweden & 0.22 & 0.40 & 0.93 & 0.81 & 0.61 & 0.31 & 0.28 & 0.30 & 0.27 & 0.22 & 0.15 & 0.13 \\
\hline United Kingdom & 0.47 & 0.60 & 0.96 & 0.80 & 0.79 & 0.73 & 0.70 & 0.61 & 0.54 & 0.41 & 0.30 & 0.15 \\
\hline
\end{tabular}

Source: Authors' own simulations based on EUROMOD tax and benefit calculations.

Notes:

The simulation is based on the benchmark scenario with hours-of-work elasticity $\varepsilon=0.1$ and participation elasticities $\eta=0.4$ in deciles 1 and $2, \eta=0.3$ in deciles 3 and $4, \eta=0.2$ deciles 5 and $6, \eta=0.1$ in deciles 7 and $8, \eta=0$ in deciles 9 and 10 .

Column (1) reports the fraction of the population gaining from the demogrant policy.

Column (2) reports the fraction of the employed population gaining from the working poor policy (those not working are not affected by the policy).

Columns (3) to (12) report the fraction of individuals gaining from the working poor policy in each decile (in computing deciles, workers are ranked by family disposable income). 


\section{Figure 1a: Effective marginal tax rates (Nordic)}

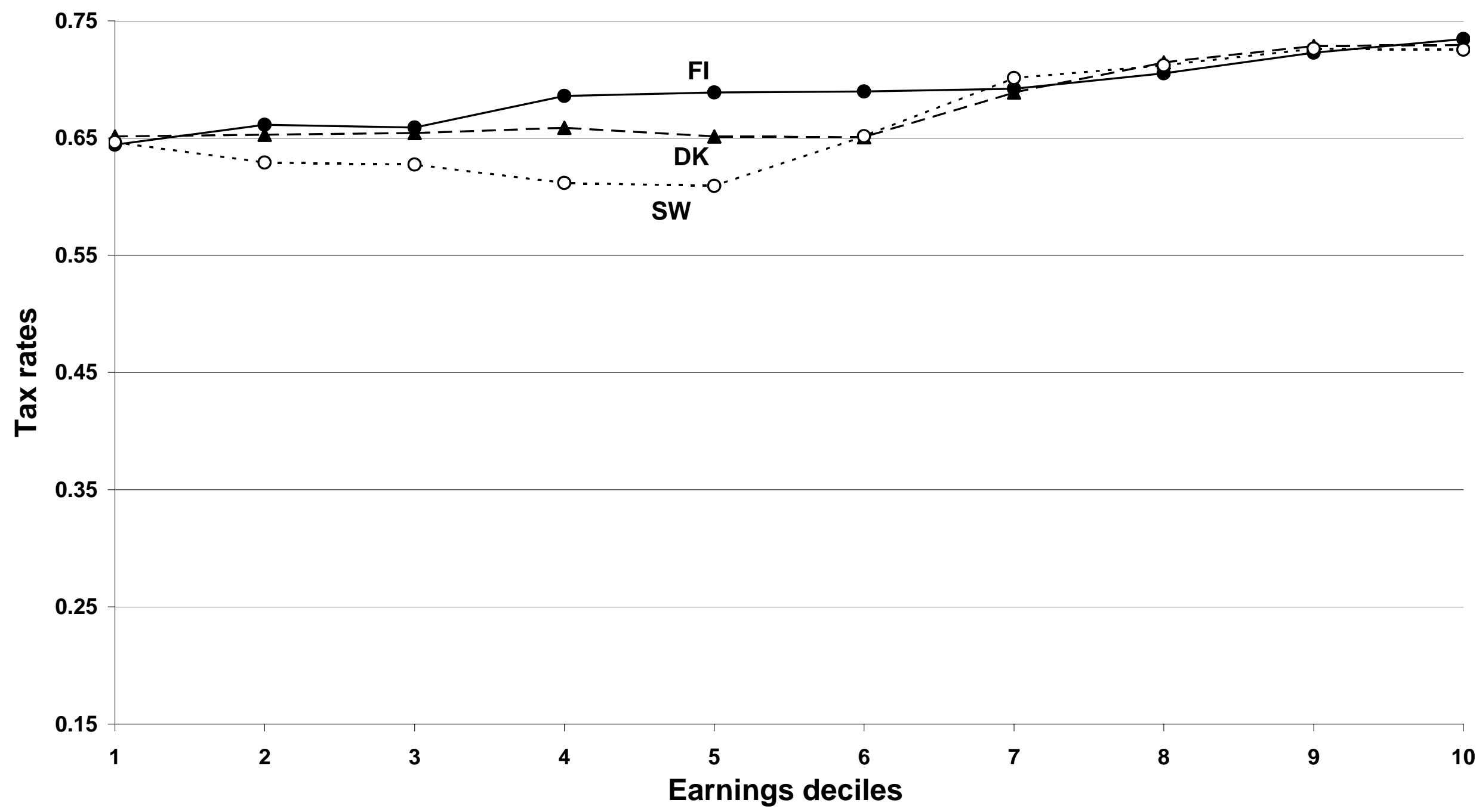

Source: EUROMOD tax and benefit calculations.

Note: The earnings deciles are based on individual earnings of those aged 18 to 59 who have been working the full year. The effective marginal tax rate is computed by increasing earnings of the individual by $3 \%$ and measuring the change in all taxes and benefits relative to the increase in earnings. 


\section{Figure 1b: Effective marginal tax rates (Continental)}

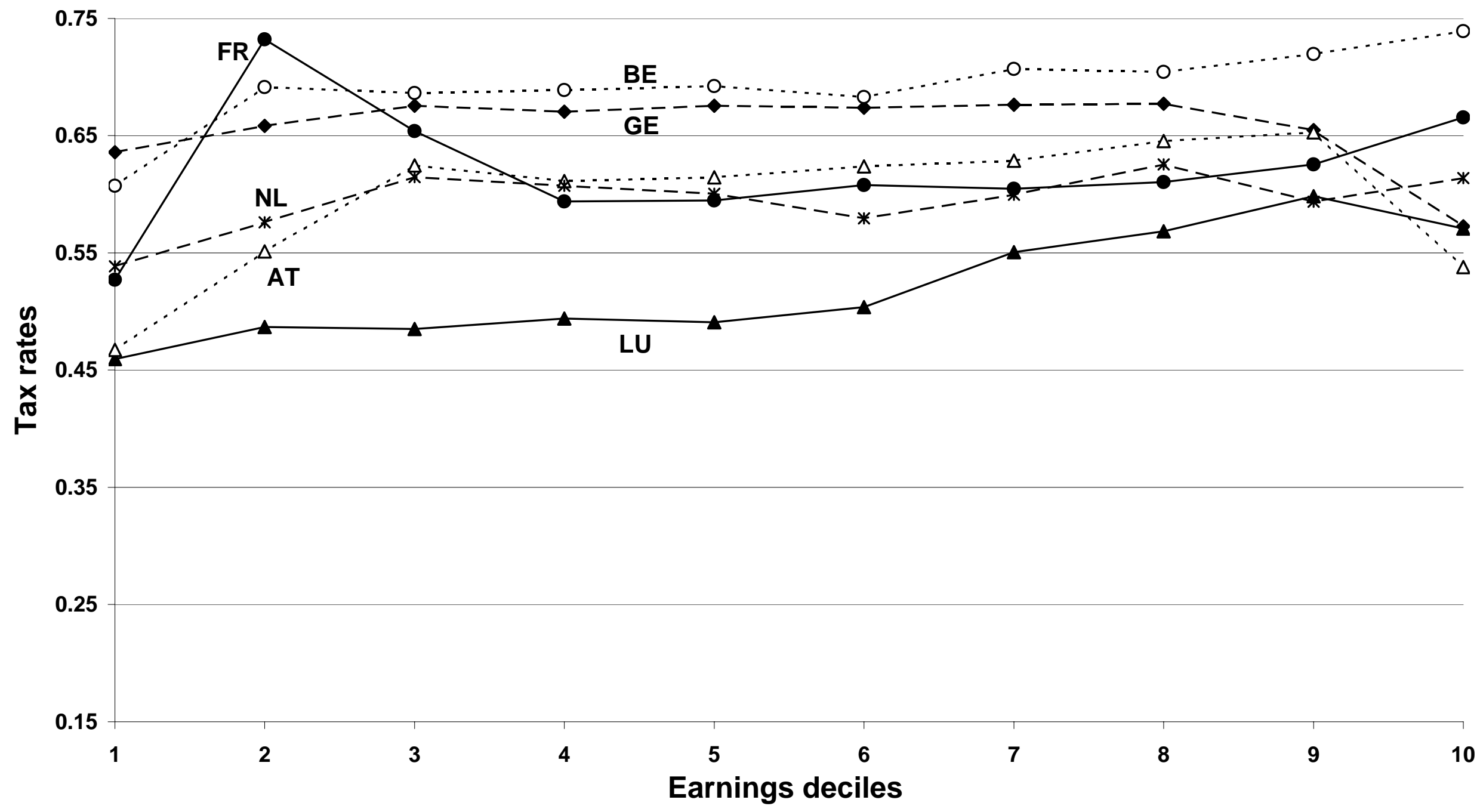

Source: EUROMOD tax and benefit calculations.

Note: The earnings deciles are based on individual earnings of those aged 18 to 59 who have been working the full year. The effective marginal tax rate is computed by increasing earnings of the individual by $3 \%$ and measuring the change in all taxes and benefits relative to the increase in earnings. 


\section{Figure 1c: Effective marginal tax tates (Anglo-Saxon+Southern)}

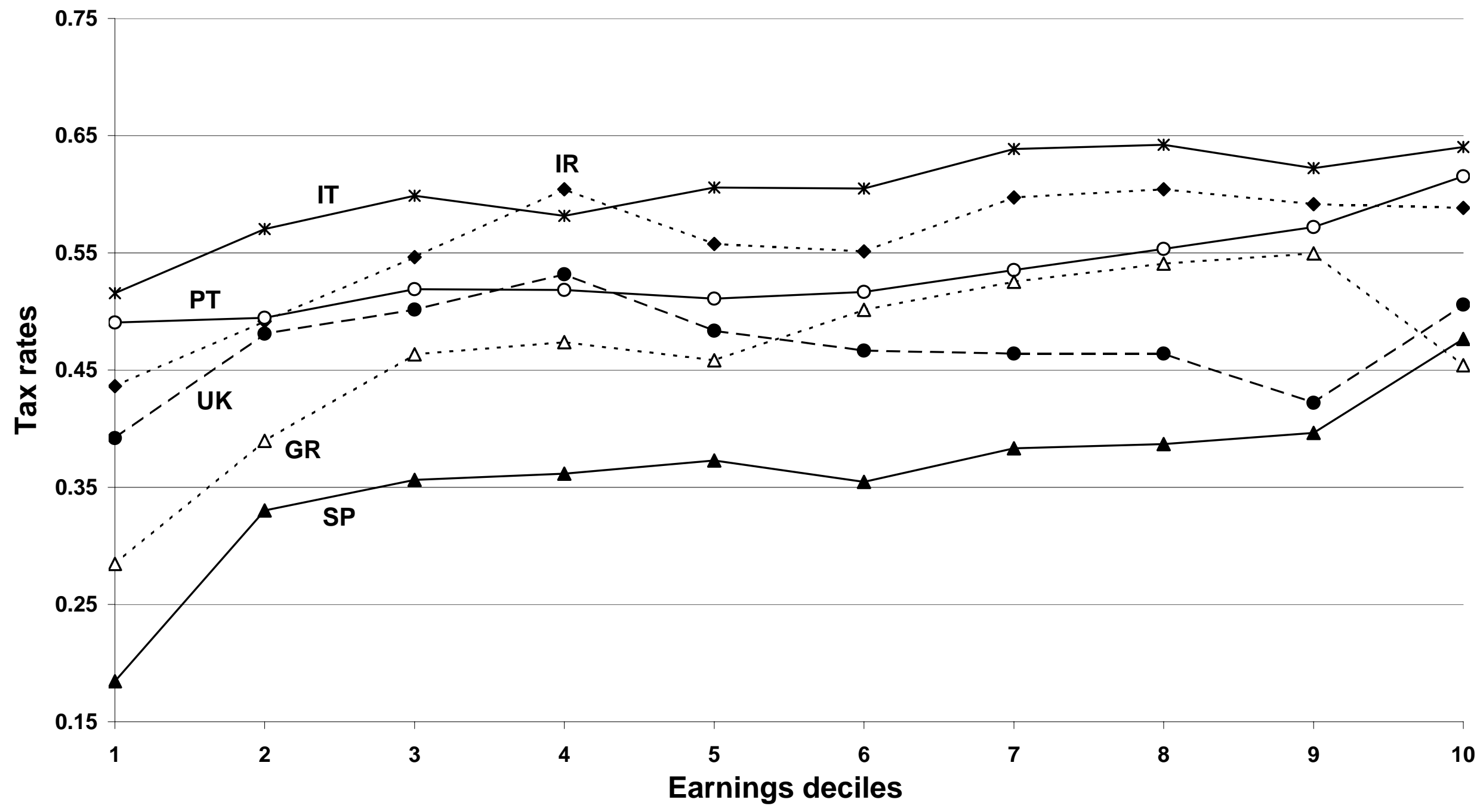

Source: EUROMOD tax and benefit calculations.

Note: The earnings deciles are based on individual earnings of those aged 18 to 59 who have been working the full year. The effective marginal tax rate is computed by increasing earnings of the individual by $3 \%$ and measuring the change in all taxes and benefits relative to the increase in earnings. 


\section{Figure 2a: Participation tax rates (Nordic)}

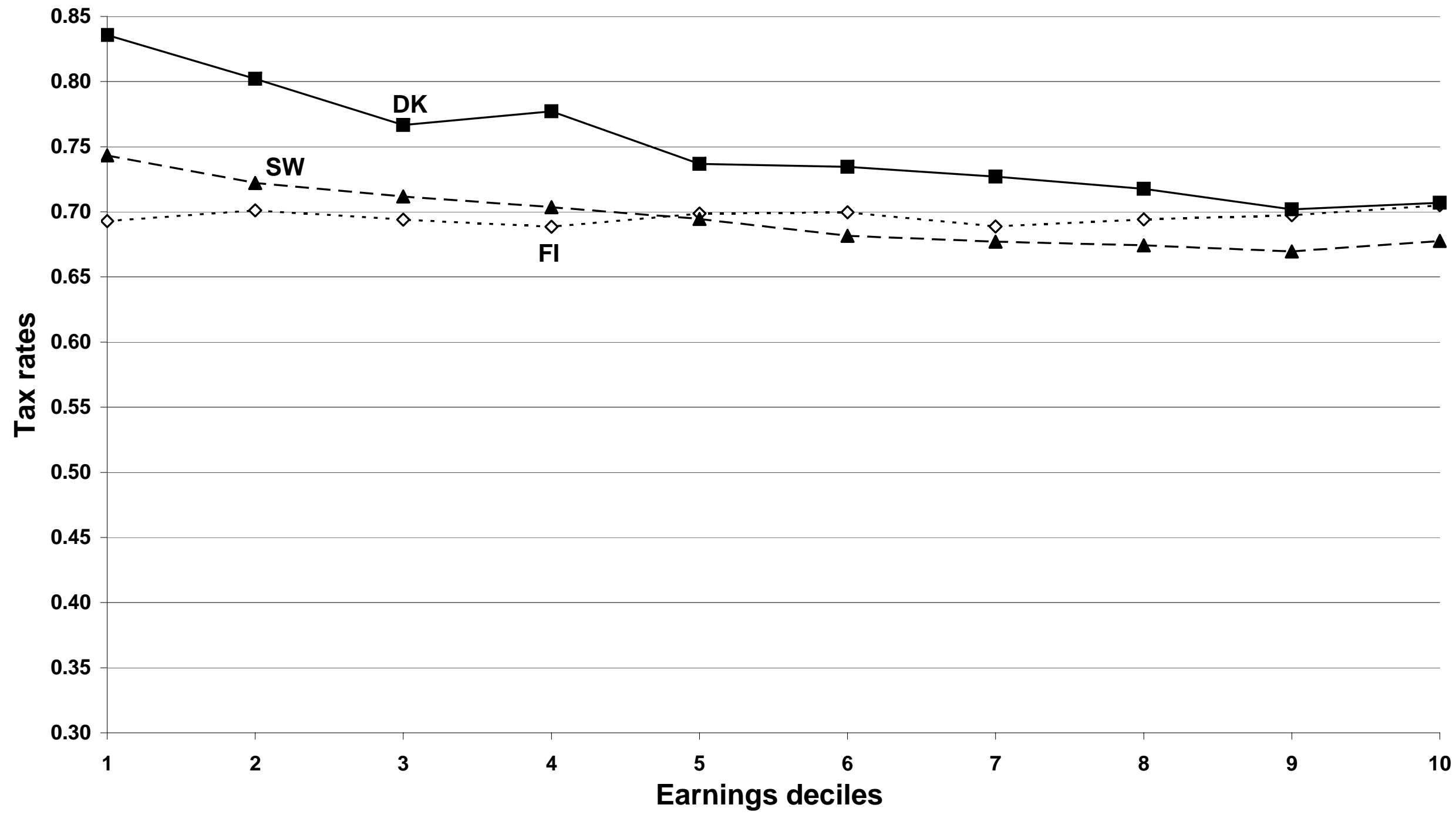

Source: EUROMOD tax and benefit calculations.

Note: The earnings deciles are based on individual earnings of those aged 18 to 59 who have been working the full year. The participation tax rate is computed by setting earnings equal to zero and measuring the change in all taxes and benefits as a share of the actual earnings of the individual. 


\section{Figure 2b: Participation tax rates (Continental)}

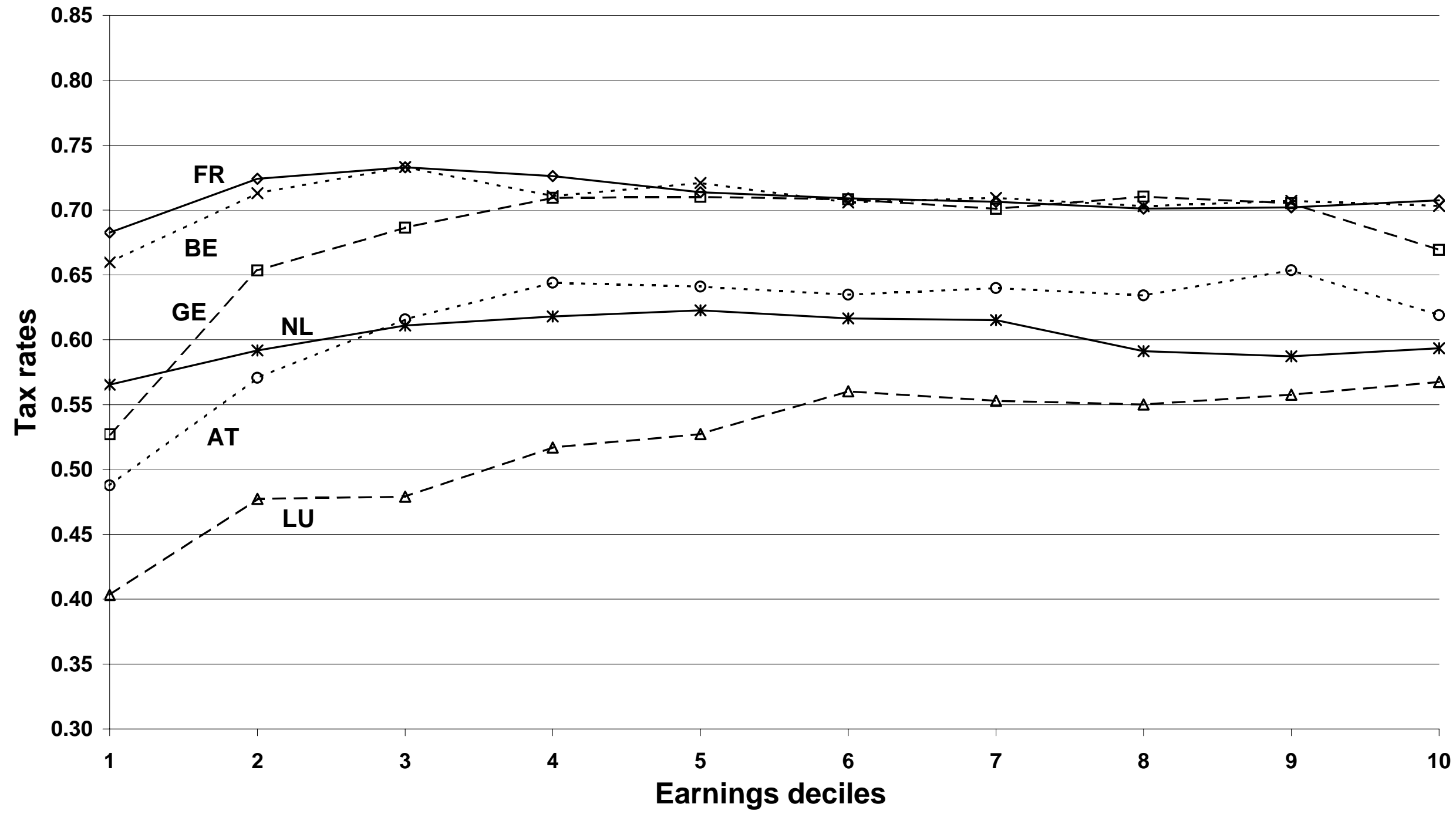

Source: EUROMOD tax and benefit calculations.

Note: The earnings deciles are based on individual earnings of those aged 18 to 59 who have been working the full year. The participation tax rate is

computed by setting earnings equal to zero and measuring the change in all taxes and benefits as a share of the actual earnings of the individual. 
Figure 2c: Participation tax rates (Anglo-Saxon+Southern)

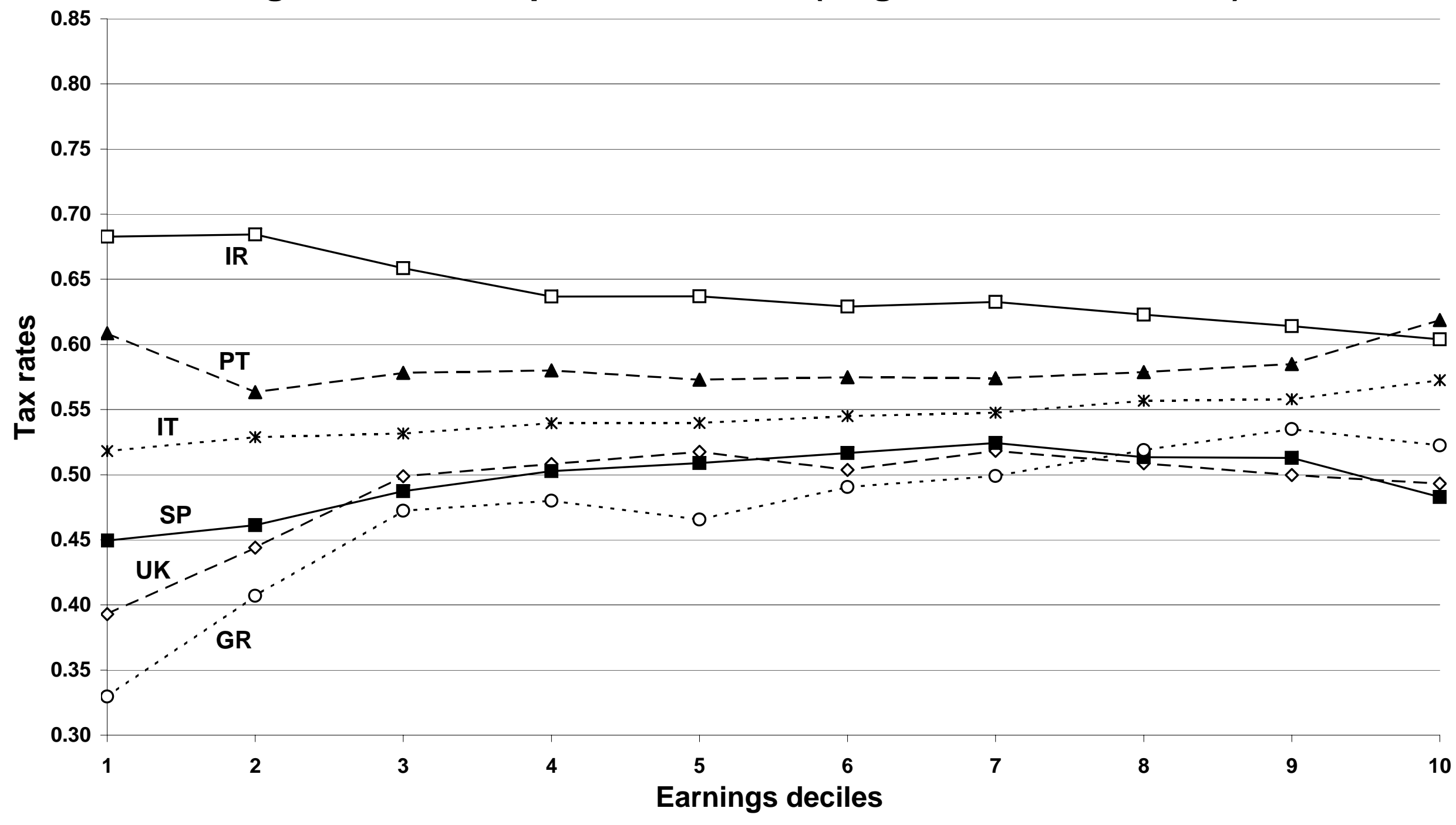

Source: EUROMOD tax and benefit calculations.

Note: The earnings deciles are based on individual earnings of those aged 18 to 59 who have been working the full year. The participation tax rate is computed by setting earnings equal to zero and measuring the change in all taxes and benefits as a share of the actual earnings of the individual. 
Figure 3a: Earnings inequality

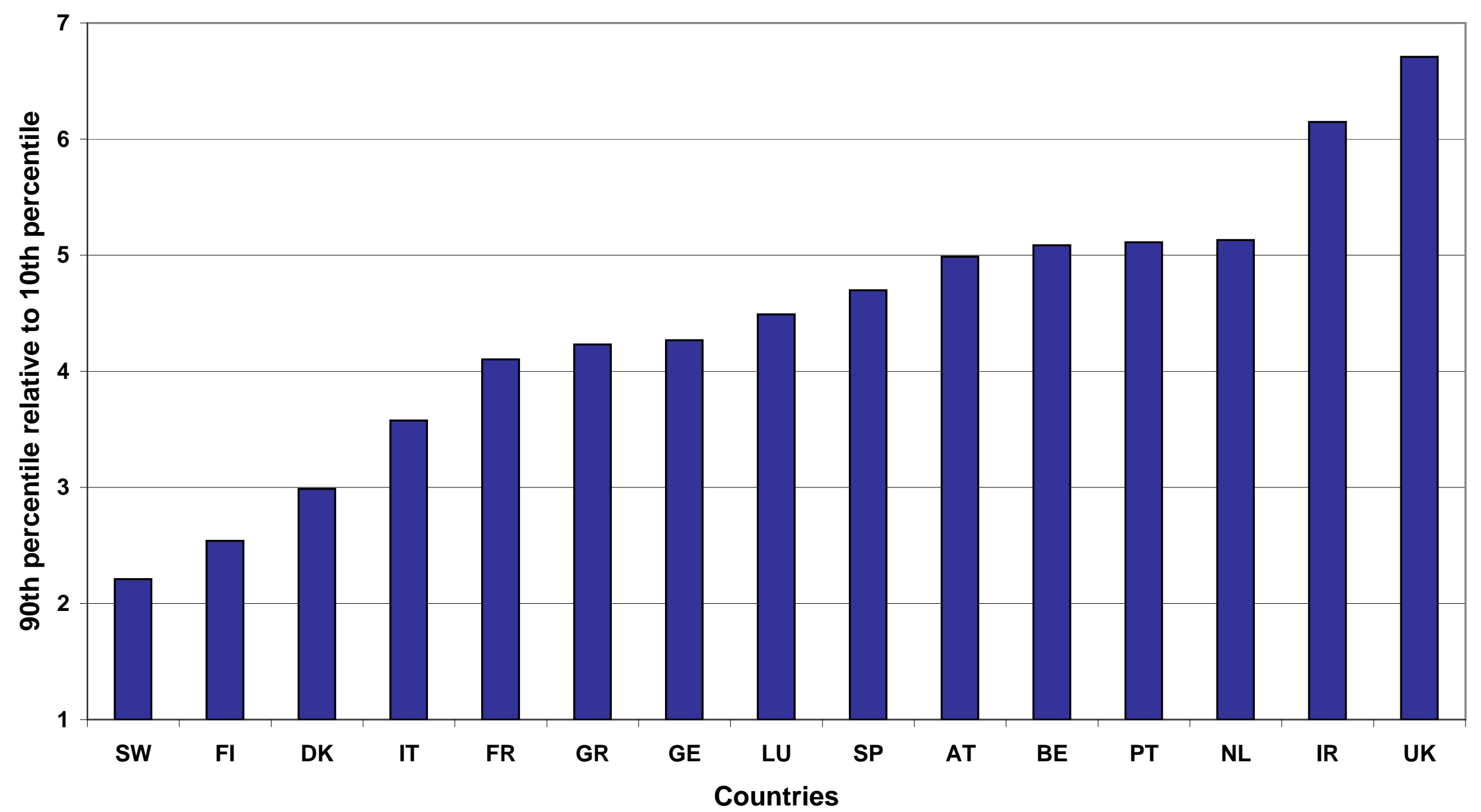

Source: EUROMOD calculations.

Note: The earnings deciles are based on individual earnings of those aged 18 to 59 who have been working the full year. 
Figure 3b: Earnings inequality

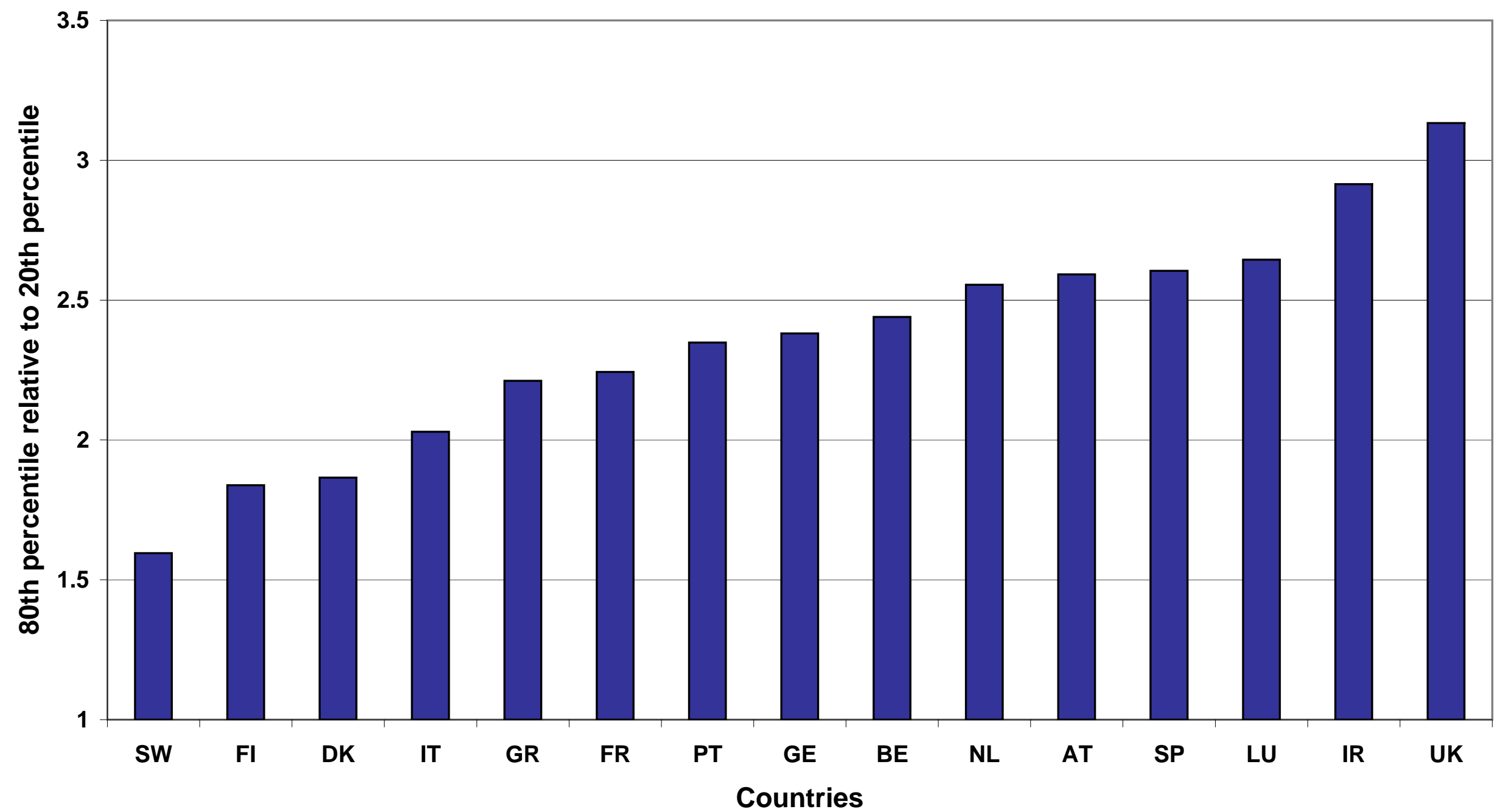

Source: EUROMOD calculations.

Note: The earnings deciles are based on individual earnings of those aged 18 to 59 who have been working the full year. 
Table A1: Summary of taxes on workers, 1998 (where relevant, rates shown for a single full-time blue-collar private sector employee with no other income and no non-standard expenses)

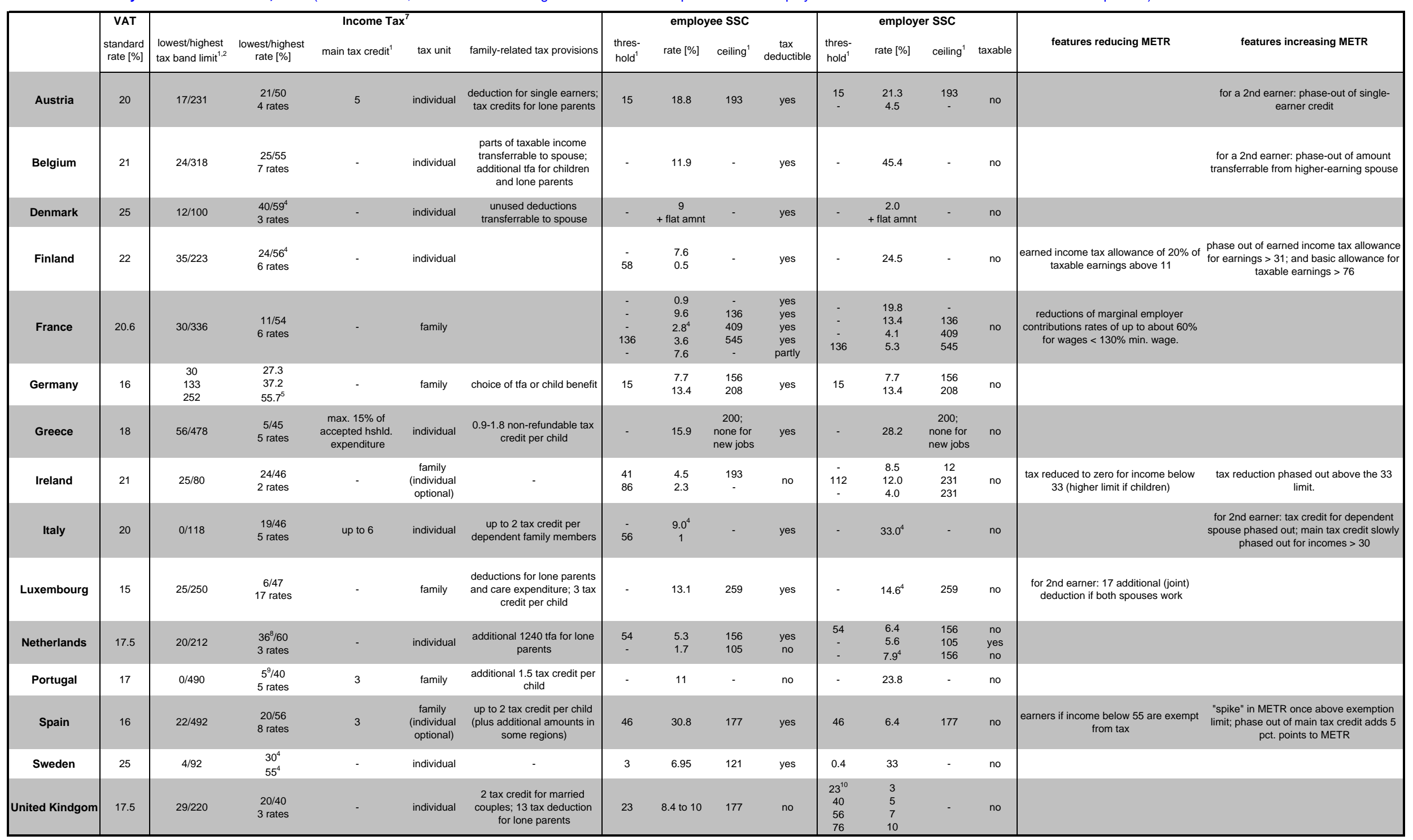

Notes: tfa $=$ tax free allowance

in $\%$ of median gross employment income (not including employer social security contributions)

after adding any standard tax free allowances, deductions or exemptions available to single employees

insurance is voluntary

(t)

firity Surplus Tax" for German unification. MTR increases linearly inbetween lower and middle; and middle and top tax band limits.

inclualing regional income taxes where applicable

including pension contributions (same tax base as income tax)

${ }^{9}$ effective rate taking into account the allowance of $70 \%$ of the tax base for low incomes
10 all earnings are subject to the applicable rate once they exceed these threshold levels 


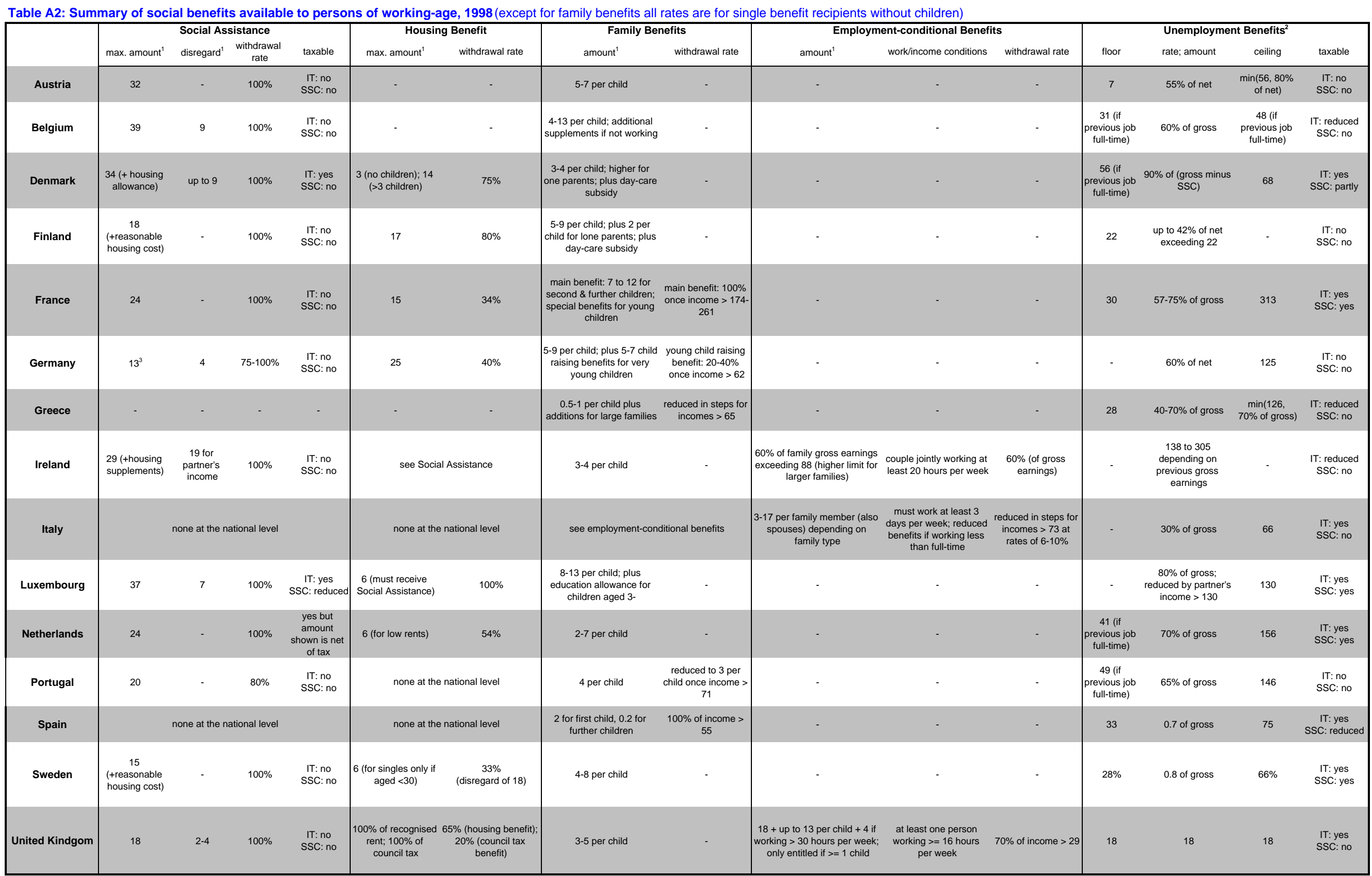

Notes: IT = income tax; SSC = social security contributions

byer social security contributions)

ent (after any waiting period if applicable) for persons aged 30+. Insurance is to some extent voluntary in Denmark,

${ }^{3}$ West Germany 
Table A3. Aggregate variables: Participation rate, UB recipients, and consumption tax

\begin{tabular}{|c|c|c|c|}
\hline Country & $\begin{array}{l}\text { Participation rate } \\
20-59 \text { years old } \\
\text { (1) }\end{array}$ & $\begin{array}{c}\text { UB recipients / non } \\
\text { working population } \\
(2)\end{array}$ & $\begin{array}{l}\text { Consumption } \\
\text { tax rate } \\
\text { (3) }\end{array}$ \\
\hline Austria & $75.1 \%$ & $9.0 \%$ & $20.8 \%$ \\
\hline Belgium & $67.6 \%$ & $21.1 \%$ & $17.7 \%$ \\
\hline Denmark & $80.8 \%$ & $21.4 \%$ & $36.6 \%$ \\
\hline Finland & $73.0 \%$ & $28.1 \%$ & $31.3 \%$ \\
\hline France & $70.1 \%$ & $31.4 \%$ & $20.1 \%$ \\
\hline Germany & $73.7 \%$ & $13.8 \%$ & $16.1 \%$ \\
\hline Greece & $64.3 \%$ & $9.7 \%$ & $16.4 \%$ \\
\hline Ireland & $67.9 \%$ & $8.8 \%$ & $27.7 \%$ \\
\hline Italy & $55.9 \%$ & $7.3 \%$ & $15.5 \%$ \\
\hline Luxembourg & $69.2 \%$ & $4.3 \%$ & $24.5 \%$ \\
\hline Netherlands & $76.0 \%$ & $12.7 \%$ & $19.6 \%$ \\
\hline Portugal & $75.1 \%$ & $14.1 \%$ & $23.3 \%$ \\
\hline Spain & $58.7 \%$ & $23.1 \%$ & $14.8 \%$ \\
\hline Sweden & $77.9 \%$ & $19.0 \%$ & $20.5 \%$ \\
\hline United Kingdom & $76.2 \%$ & $10.0 \%$ & $17.5 \%$ \\
\hline
\end{tabular}

Source: Columns (1) and (2): OECD Labour Force Statistics. Columns (3): OECD National Accounts (2003), Volume II, 19902001 and OECD Revenue Statistics (2002), 1965-2001

Notes: All figures are from 1998. Column (1) reports the fraction of the population aged 20 to 59 currently working. Column (2) reports the fraction of the non-working population (aged 20 to 59) that is unemployed and entitled to unemployment benefits. Column (3) reflects the authors' own calculations based on the methodology of Mendoza et al. (1994). Referring to OECD National Accounts and Revenue Statistics classification, the consumption tax rate is given by the ratio of the sum of general consumption taxes (5110) and excise taxes (5121) to national consumption expenditure which includes consumption by households (Cp), non-profit institutions (CNPIH) and government (G), but excludes government wage outlays (GW). The formula is $(5110+5121) /(C p+C N P I H+G-G W-(5110+5121))$. 